\title{
Interaction of Urban Rivers and Green Space Morphology to Mitigate the Urban Heat Island Effect: Case-Based Comparative Analysis
}

\author{
Yunfang Jiang $1,2,3, * \mathbb{D}$, Jing Huang ${ }^{1,2,3}$, Tiemao Shi ${ }^{4, *}$ and Hongxiang Wang 5 \\ 1 School of Urban and Regional Science, East China Normal University, Shanghai 200241, China; \\ jhuang@stu.ecnu.edu.cn \\ 2 The Center for Modern Chinese City Studies, East China Normal University, Shanghai 200241, China \\ 3 Research Center for China, Administrative Division, East China Normal University, Shanghai 200241, China \\ 4 Institute of Spatial Planning and Design, Shenyang Jianzhu University, Shenyang 110168, China \\ 5 School of Journalism and Communication, Sichuan International Studies University, \\ Chongqing 400031, China; elainewhx@163.com \\ * Correspondence: yfjiang@re.ecnu.edu.cn (Y.J.); tiemaos@sjzu.edu.cn (T.S.)
}

\section{check for}

updates

Citation: Jiang, Y.; Huang, J.; Shi, T.; Wang, H. Interaction of Urban Rivers and Green Space Morphology to Mitigate the Urban Heat Island Effect: Case-Based Comparative Analysis. Int. J. Environ. Res. Public Health 2021, 18, 11404. https://doi.org/10.3390/ ijerph182111404

Academic Editors: Alfredo Rocha, Ricardo Almendra and Teodoro Georgiadis

Received: 26 August 2021

Accepted: 25 October 2021

Published: 29 October 2021

Publisher's Note: MDPI stays neutral with regard to jurisdictional claims in published maps and institutional affiliations.

Copyright: (c) 2021 by the authors Licensee MDPI, Basel, Switzerland. This article is an open access article distributed under the terms and conditions of the Creative Commons Attribution (CC BY) license (https:// creativecommons.org/licenses/by/ $4.0 /)$.

\begin{abstract}
The spatial morphology of waterfront green spaces helps generate cooling effects to mitigate the urban heat island effect (UHI) in metropolis cities. To explore the contribution and influence of multi-dimensional spatial indices on the mitigation of UHIs, the green space of the riparian buffer along 18 river channels in Shanghai was considered as a case study. The spatial distribution data of the land surface temperature (LST) in the study area were obtained by using remote sensing images. By selecting the related spatial structure morphological factors of the waterfront green space as the quantitative description index, the growth regression tree model (BRT) was adapted to analyze the contribution of various indexes of the waterfront green space on the distribution of the LST and the marginal effect of blue-green synergistic cooling. In addition, mathematical statistical analysis and spatial analysis methods were used to study the influence of the morphological group (MG) types of riparian green spaces with different morphological characteristics on the LST. The results showed that in terms of the spatial structure variables between blue and green spaces, the contribution of river widths larger than $30 \mathrm{~m}$ was more notable in decreasing the LST. In the case of a larger river width, the marginal effect of synergistic cooling could be observed in farther regions. The green space that had the highest connectivity degree and was located in the leeward direction of the river exhibited the lowest LST. In terms of the spatial morphology, the fractional cover values of the vegetation $(\mathrm{Fv})$ and area (A) of the green space were the main factors affecting the cooling effect of the green space. For all MG types, a large green patch that had a high green coverage and connectivity degree, as well as was distributed in the leeward direction of the river, corresponded to the lowest LST. The research presented herein can provide methods and development suggestions for optimizing spatial thermal comfort in climate adaptive cities.
\end{abstract}

Keywords: urban heat island (UHI); blue-green space; spatial morphology; urban cooling effect (UCI); boosted regression trees (BRT); marginal effect (ME); Shanghai

\section{Introduction}

With the expansion of urban areas and intensification of the urbanization process, the urban heat island (UHI) effect is becoming a significant urban issue. Natural surfaces, such as vegetation areas and riparian areas, are being replaced by impervious surfaces, resulting in increased long-wave radiation [1-3]. Impervious surfaces absorb more solar radiation due to their low reflectivity and high absorptivity, thereby generating a higher land surface temperature (LST) that increases the air temperature, due to the increased long-wave radiation, and induces the urban heat island effect [4-7]. The high-temperature environment 
induced by urban heat islands affects human thermal comfort and aggravates air pollution, thereby adversely influencing human health [8-11]. The urban blue-green space, including waterbodies (rivers, lakes, and reservoirs) and green spaces (parks, gardens, grassland forests, etc.), has a significant ecological function in mitigating UHIs [12,13]. Urban green space can most effectively emit longwave radiation to cool the surface because it has high emissivity and efficiently consumes shortwave radiation through evaporation. At the same time, the high heat capacity attribute and the evaporation latent heat of waterbodies, which can absorb more heat and reduce the ambient temperature, produce the constant cooling effect. Integration of the distribution of blue-green spaces in urban built-up area, therefore, would be essential for the mitigation of the UCI of urban regions [14-16].

In the context of the effect of the urban cooling islands of green space (UGCIs), the influence of factors related to the spatial morphology and distribution on the LST reduction, including the area, shape index, green space coverage, building layout, and other environmental elements, has been extensively considered [17-20]. Green patches with large areas can reduce the surface temperature of green spaces and provide a stable cooling effect [21,22]. Green patches with low landscape shape index (LSI) values are conducive to the cooling effect when the area of green space is smaller than $5.6 \mathrm{ha}$, but the opposite occurs for larger green spaces [23]. The boundary of green patches has minimal contact with the external environment, thereby facilitating the stable maintenance of the low temperature of the green space [24-26]. Green coverage, which is generally evaluated in terms of the normalized difference vegetation index (NDVI) or fractional cover values of the vegetation space $(\mathrm{Fv})$, is negatively correlated with the land surface temperature (LST) in the summer [27-29]. Green space with large Fv values has an obvious cooling effect and a complex vegetation structure is helpful to prevent water evaporation [30]. Moreover, the surface albedo, which represents the ability of surface objects to absorb and reflect the surrounding radiation, is negatively correlated with the LST to a certain extent [31]. In addition, the connectivity degree of green spaces considerably influences the cooling effect of such spaces. The DPC index describing connectivity degree can accurately reflect the connectivity level among green patches and inter-connected green spaces provide a higher cooling effect over adjacent areas [32,33].

Recent studies of the impact factors of the waterbody cooling island (WCI) effect have mainly focused on the area, width, and shape of the waterbody and its location in the dominant wind direction [34-36]. Based on the ASTER image data of Beijing, the cooling intensity and efficiency of waterbodies were related to its area, geometry, location, and building proportion, as the study examined the cooling effect from 197 waterbodies [25]. The effect of the area of waterbodies on thermal environment is much more significant than that of water depth according to the case study by ENVI-met microclimate simulation [13]. As a linear waterbody, wider rivers have a more notable ability to regulate the thermal environment [37,38]. Moreover, a waterbody exerts a greater cooling effect over the area in the leeward direction $[39,40]$. Compared with that of the windward area, the cooling intensity of the leeward area was $1.5^{\circ} \mathrm{C}$ higher [38]. The temperature difference between the leeward and windward could reach $2{ }^{\circ} \mathrm{C}$ in a large area of a waterbody [41].

The blue-green synergistic cooling effect is considerably higher than the single ecological element effect $[42,43]$. The evapotranspiration of water bodies is stronger under the influence of a green space [44]. Vegetation can affect the water radiation balance, promote air convection, and reduce the off-shore temperature through shading and transpiration [45]. The cooling effect of rivers with a high vegetation coverage is higher than that of rivers with no vegetation [39]. Increasing the vegetation ratio in riparian areas can effectively enhance the cooling effect [46]. The forest buffers provide different efficiencies regarding the reduction of stream air temperature in different periods of summer based on the modelling and analysis of the cooling effect of five rivers in western-Washington state in the summer before and after logging [47]. The maximum temperature difference between the two scenarios with and without rivers around the residential area can reach $1.6^{\circ} \mathrm{C}$ based on CFD numerical simulation in Tokyo [48]. A river with a width of $35 \mathrm{~m}$ can 
lead to a decrease of approximately $1-1.5^{\circ} \mathrm{C}$ in the ambient temperature and the decrease can be increased if green space is present on both sides of the river [49]. The case study of an urban region in Fujian indicated that green spaces adjacent to rivers can exert obvious synergistic cooling effects, which can intensify the cooling effect by approximately $2.7^{\circ} \mathrm{C}$ [22] The green space network pattern in waterfront areas, especially with a high connectivity degree, considerably influences the transportation of cold air in urban rivers [50]. The comprehensive cooling effect of the optimized blue-green space network is greater than that of any single green space element in Shanghai city [42].

In the study of the influencing factors of blue-green spaces on the cooling effect, field measurement, remote sensing technology, and numerical simulation methods are usually used. The field measurement method studies the cooling effect of blue-green spaces by obtaining the temperature data of local specific points [36,39]. However, the measured workload is large and there are many interference factors that affect the measurement results. Numerical simulation is a three-dimensional dynamic simulation based on computational fluid mechanics. At present, the commonly used software platforms are ENVI-met, fluent, WRF, Airpark, etc. Among them, ENVI-met is widely used to simulate the microclimate of green spaces or waterbodies. The maximum simulation grid scale of ENVI-met software is limited to $2 \times 2 \mathrm{~km}$, which is more suitable for the micro-scale [13,50]. The technology of RS and GIS can provide continuous LST data at the macro-scale and can also provide overall data for urban meso-scale research. In recent years, it has been widely used in the research field of urban thermal environments [22,35,51].

The focus of research on the cooling island effect is gradually shifting to more complex built-up space environments. The existing studies quantitatively examined the cooling effect correlated to the macro-morphological factors of blue-green spaces or to specific factors at the micro-level. However, the impact of the spatial morphology at the urban meso-level as a controlling index must be more extensively examined for application to urban green space planning [32,52]. The three-dimensional features of the internal structure of green spaces and the features of the surrounding areas influence the thermal environment distribution of green space patches. These spatial environmental indicators must be integrated with the characteristics of the spatial structure and morphological factors to explore the cooling effect. Notably, urban waterfront areas are usually the first preference of urban residents as a public activity space. To maximize the urban cold island effect in the hot season, the spatial pattern of green spaces located on both sides of urban rivers is thus the focus of climatic adaptability planning in urban building areas.

The city of Shanghai is located in a plain river network region, in which many rivers intersect and are connected across the built-up environment. In this study, typical river systems in the study area at the urban-meso-spatial scale in Shanghai were selected. A machine learning algorithm was used to analyze the contribution ratio of each structural and morphological factor to the LST decrease in the waterfront green space and the marginal effect of blue-green synergistic cooling in river corridors. The morphological group (MG) types with notable cooling effects, as classified by the dominant spatial index, were used to identify the morphological characteristics of the waterfront green space considered for microclimate adaptability. Subsequently, the index describing the quantitative spatial aspects could be applied to standardize the green space planning and design practice.

\section{Study Area and Methodology}

\subsection{Study Area}

Shanghai is located at $120^{\circ} 51^{\prime}-122^{\circ} \mathrm{E}$ and $30^{\circ} 41^{\prime}-31^{\circ} 53^{\prime} \mathrm{N}$; this region has a typical subtropical monsoon climate, with hot and humid summers and cold and dry winters. The hot weather in Shanghai occurs in July and August. In 2017, there were 28 days in July and 17 days in August in which the daily maximum temperature in Shanghai exceeded $35^{\circ} \mathrm{C}$ [53]. Coupled with intensive land use and high population density in the built-up area, the UHI phenomenon was more significant in the past twenty years. The proportion 
of UHI area in the jurisdiction area was $9.47 \%$ in 2000, which reached $20.49 \%$ in 2009 and $34.18 \%$ in 2017 [54].

The overall terrain of the city area is a broad and alluvial plain with an average altitude of about $4 \mathrm{~m}$. The rivers within the jurisdiction originate from many lakes and upper reaches on the eastern edge of the Taihu Lake Basin. The river network density of Shanghai is $4.53 \mathrm{~km} / \mathrm{km}^{2}$ and the waterbody surface ratio of the rivers and lakes is $9.79 \%$ [55]. The styles of waterscapes are mainly river corridors, especially the Huangpu River section flowing through the central area from the south to north, which is the most important main river in the study area.

A relatively holistic area, which is enclosed by the east-west and north-south segments of the Huangpu River, was selected as the study area. The green patches in the area are ecologically diverse and the waterfront public space is characterized by multiple patterns. Small and medium parks are scattered in the city center, while large green spaces and agricultural land are mostly distributed in the suburbs. Due to the high-density built-up area in the city center, the distribution of the UHIs and the difference in the spatial thermal environments in this area are notable. In the study area, the water system of the backbone river based on the "2017 Shanghai River Channel (Lake) Report" was considered and the river buffer area was identified considering the river width and boundary of the urban blocks and roads (Figure 1).

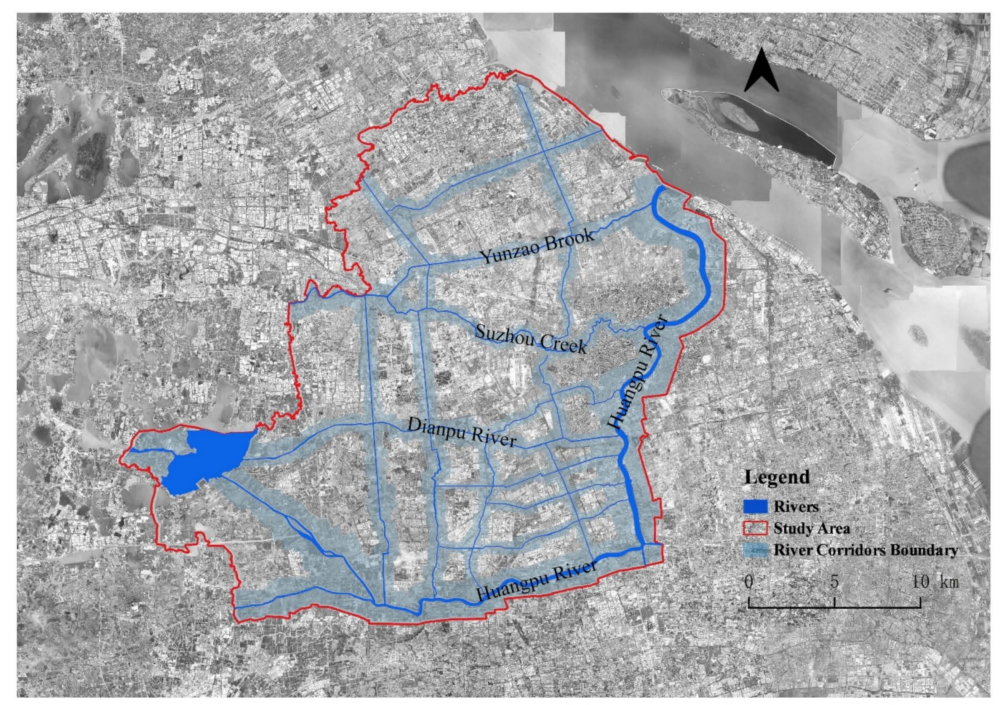

Figure 1. Locations of the backbone river corridors and their river buffer areas in the study area.

\subsection{Data and Methods}

\subsubsection{Research Framework}

The methodological framework of this study is shown in Figure 2. The typical process for cooling effect research involves four key steps: (1) The first step involves the retrieval of the land surface temperature in the study area by using a radiative transfer equation (RTE) and extraction of the urban surface temperatures based on band 10 of Landsat 8 remote sensing images. (2) The second step involves the establishment of a geospatial database of the river corridors and waterfront green spaces. High-resolution aerial image data and administrative topographic vector data were combined with manual field surveys to establish a spatial distribution database of both the urban river corridors and waterfront green spaces. Based on the spatial database, the green space morphological index and spatial structure factors between the waterbodies and green space were quantified. (3) The third step involves, the correlation analysis between the LST values and morphological factors of the blue-green space. Using spatial analysis methods based on the BRT model, on mathematical statistics, and on the classification and grouping of spatial data, the influence of the multi-dimensional index factors of the waterfront green space in a river 
corridor was clarified and the cooling characteristics of the selected spatial morphological factors were analyzed. Based on the cooling effect of these morphological indices, the spatial distribution mechanism of the urban cooling island effect of blue-green spaces was explained.

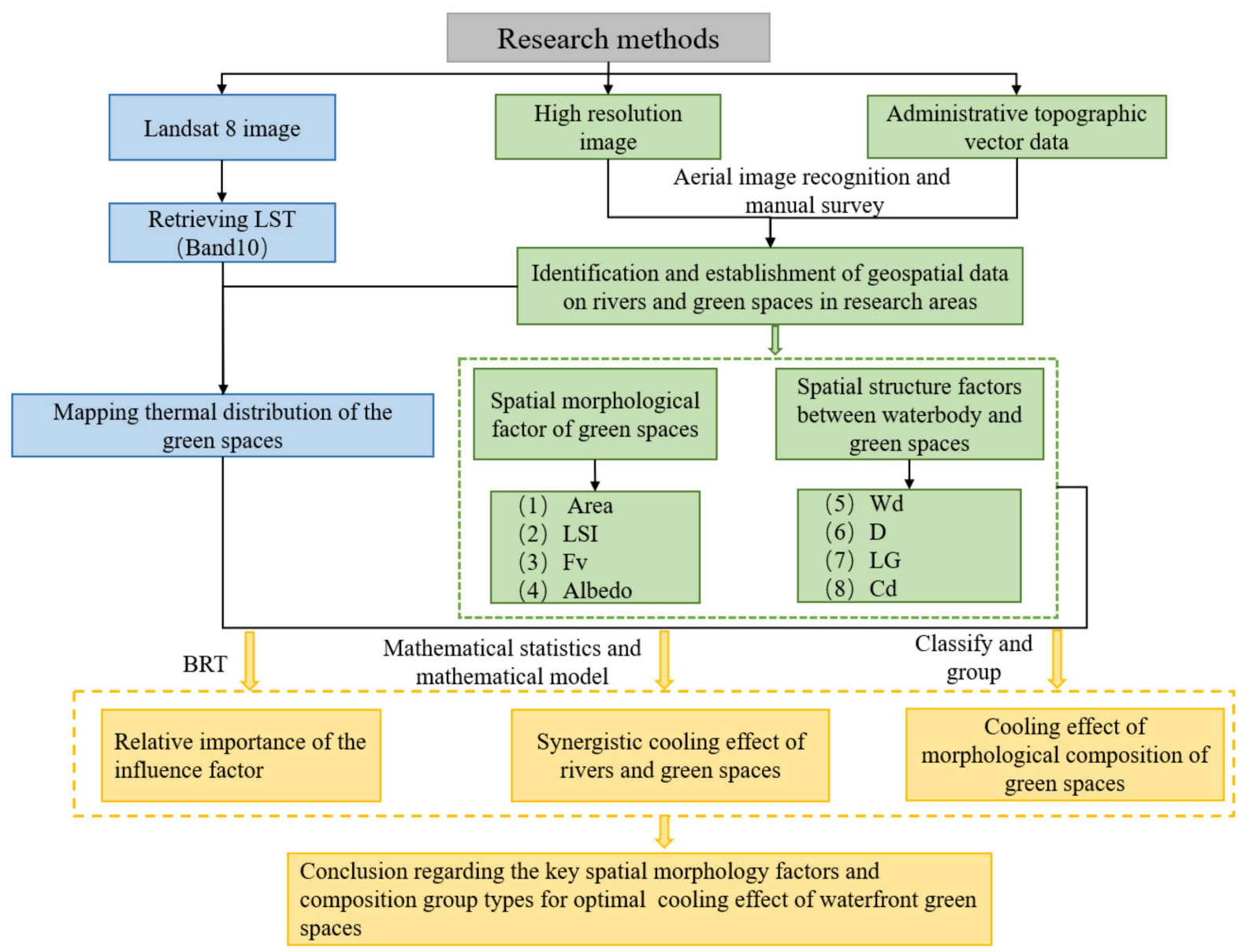

Figure 2. Process flow of the study. BRT: boosted regression trees; LSI: landscape shape index; Fv: fractional cover values of vegetation space; Wd: width of river; D: distance to riverbank; LG: location of greenspace; Cd: connectivity degree.

\subsubsection{Land Surface Temperature}

To retrieve the land surface temperature, the surface temperature was determined using the ENVI5.3 software. The urban surface temperatures were extracted based on the Landsat 8 TIRS image data obtained by the United States Geological Survey (USGS) at 10:25 on 24 August 2017, under a cloud cover of $0.4 \%$. This process was implemented in two steps. First, the band 10 thermal infrared data of Landsat 8 thermal infrared sensor (TIRS) images were subjected to radiometric calibration and atmospheric correction based on the fast line-of-sight atmospheric analysis of the spectral hypercubes (FLAASH) model in the ENVI software. Second, band 10 of the TIRS image was used to retrieve the land surface temperature (LST). In general, three methods can be used for Landsat-TM data retrieval, namely the radiative transfer equation (RTE), mono-window algorithm (MWA), and single-channel method (SCM). In this study, the RTE based on band 10 was used to retrieve the LST due to its higher accuracy compared to the other methods [56].

The principle of the radiative transfer equation (RTE) is as follows: First, the influence of the atmosphere on the surface thermal radiation is estimated. Next, the atmospheric influence is subtracted from the total amount of thermal radiation observed by the satellite 
sensors to obtain the surface thermal radiation intensity. This value is transformed to the corresponding surface temperature [51]. The calculation formula is as follows [57]:

$$
L \lambda=[\varepsilon B(T s)+(1-\varepsilon) L \downarrow] \tau+L \uparrow
$$

where $L_{\lambda}$ is the luminance value of the thermal infrared radiation received by the satellite sensor, $L \uparrow$ is the atmospheric upwelling radiance, $L \downarrow$ is the atmospheric downwelling radiance, $\varepsilon$ is the emissivity of the surface, $T s$ is the true land surface temperature, $B(T s)$ is the black body radiation intensity determined using the Plank radiation function, and $\tau$ is the atmospheric transmissivity. The three atmospheric profile data points $(\tau, L \uparrow$, and $L \downarrow$ ) can be obtained from NASA's website (http: / / atmcorr.gsfc.nasa.gov) (accessed on 25 January 2020).

The variables $\varepsilon, B(T s)$, and Ts can be calculated as follows:

$$
\begin{gathered}
\varepsilon=0.004 F v+0.986 \\
F v=\left[\left(N D V I-N D V I_{\text {soil }}\right) /\left(N D V I_{\text {veg }}-N D V I_{\text {soil }}\right)\right]
\end{gathered}
$$

where $F v$ is the fractional cover value of the vegetation space; NDVI is the normalized difference vegetation index; $N D V I_{\text {soil }}$ is the $N D V I$ value for areas that have completely bare soil or no vegetation cover, considering the empirical value $N D V I_{\text {soil }}=0.05$; and $N D V I_{\text {veg }}$ represents the $N D V I$ value of the area completely covered by vegetation, considering the empirical value $N D V I_{\text {veg }}=0.70$.

$$
\begin{gathered}
B\left(T_{S}\right)=[L \lambda-L \uparrow-\tau(1-\varepsilon) L \downarrow] / \tau \varepsilon \\
T_{S}=K_{2} / \ln \left(K_{1} / B\left(T_{S}\right)+1\right)
\end{gathered}
$$

where $K_{1}$ and $K_{2}$ are constants. For the TIRS data of Landsat-8, $K_{1}=774.89\left(\mathrm{mWm}^{-2} \mathrm{sr}^{-1} \mu \mathrm{m}^{-1}\right)$ and $K_{2}=1321.08\left(\mathrm{mWm}^{-2} \mathrm{sr}^{-1} \mu \mathrm{m}^{-1}\right)$.

The LST distribution map of the study area was obtained (Figure 3) and imported to the ArcGIS10.4 software. The zonal analyst tool of ArcGIS was used to calculate the mean LST value of each green patch.

\subsubsection{River Width Classification and Green Space Extraction in the Buffer Zone}

Rivers of different widths have different ecological cooling functions. River regulation and land use in waterfront areas are commonly related to the river channel order. A river with an estuary width of less than $30 \mathrm{~m}$ is defined as a small and a medium river by the water conservancy department in China [58]. The technical standard for the river classification of plain river networks is $30 \mathrm{~m}, 30-50 \mathrm{~m}, 50-70 \mathrm{~m}$, and more than $70 \mathrm{~m}$ [59].

In terms of the river morphological factors affecting the cooling effect, studies have shown that the width of the river and the land use along the riverside were the two fundamental factors [25,37]. Previous studies in Shanghai showed that Huangpu River had the lowest temperature zone, which provided a great impact on the thermal environment of Shanghai. The UCI of meso-scale rivers in urban suburbs was relatively obvious. The streams with small widths in the city center had little impact on the surrounding temperature [37]. The relative case study indicated that the LST mean value of Huangpu River (width of $300-770 \mathrm{~m}$ ) in the $200 \mathrm{~m}$ buffer zone was $2.90^{\circ} \mathrm{C}, 1.69{ }^{\circ} \mathrm{C}$, and $1.01{ }^{\circ} \mathrm{C}$ less than that of Suzhou Creek (50-60 m), Yunzao Brook (30-60 m), and Chuanyang River (approximately $70 \mathrm{~m}$ ), respectively [37]. Moreover, the results of a case study in Beijing city demonstrated that the width of an urban river is a key factor affecting the temperature and humidity effect of the riverside green space [60]. 


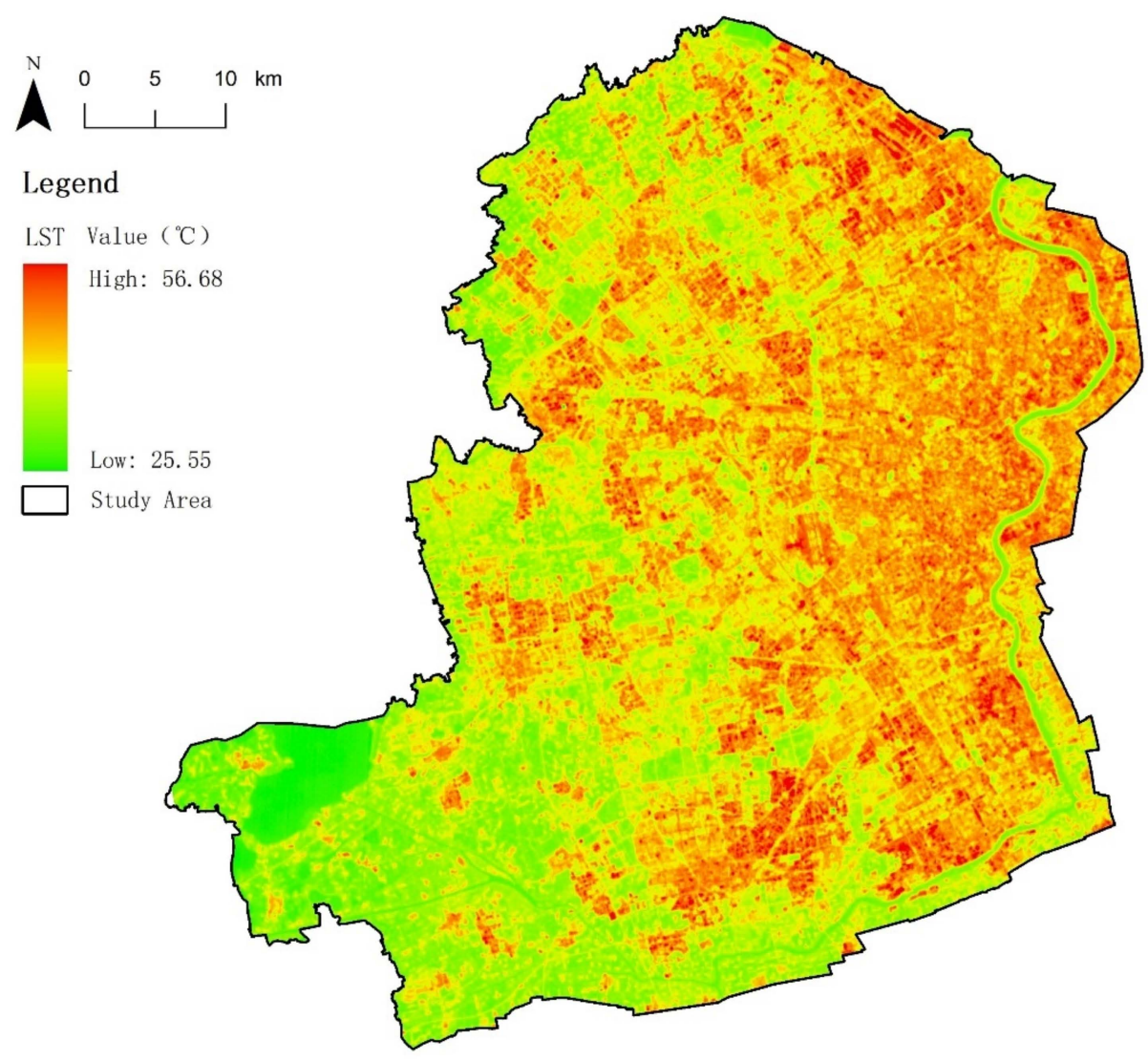

Figure 3. Distribution map of the study area.

The study of a plain river network in Wuhan city, which has the same climatic conditions as Shanghai, found that the threshold distances of the cooling effect were $550 \mathrm{~m}$, $780 \mathrm{~m}, 1000 \mathrm{~m}, 1500 \mathrm{~m}$, and $1700 \mathrm{~m}$ in different rivers regions [61]. In this study, using the river hierarchical management data and corresponding research data of different threshold distances, and also considering the notable differences in the river network distribution characteristics and LST value distributions in the study area of Shanghai, four width classifications of urban rivers in the study area were established:

(1) Width-I: the first classification pertains to rivers with a width of less than $30 \mathrm{~m}$ and the buffer zone is $500-800 \mathrm{~m}$ from the riverbank;

(2) Width-II: the second classification pertains to rivers with a width between 30 and $50 \mathrm{~m}$, and the buffer zone is $800-1500 \mathrm{~m}$ from the riverbank;

(3) Width-III: the third classification pertains to rivers with a width between 50 and $80 \mathrm{~m}$, and the buffer zone is $1000-1700 \mathrm{~m}$ from the riverbank; and

(4) Width-IV: the fourth classification pertains to rivers with a width greater than $100 \mathrm{~m}$. The width of the river channel in the study area is not in the range of $80-100 \mathrm{~m}$. The buffer zone is $1500-2500 \mathrm{~m}$ from the riverbank.

The green space in the buffer zone was extracted after the river classification. First, based on a high-resolution image of 2017 and vector data of a 1:50,000 road network topographic map of 2015, ground control points (GCPs) were selected to realize the geometric precision correction. Second, the image recognition of the river networks and green space was performed using the method of artificial recognition and field supplementary investigation to determine the spatial distribution of the river networks and each green patch in the study area. Finally, the spatial distribution of the river channels and green spaces in the river corridor, as well as its buffer area, were determined (Figure 4). 


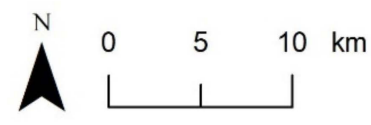

\section{Legend}

River Ranks

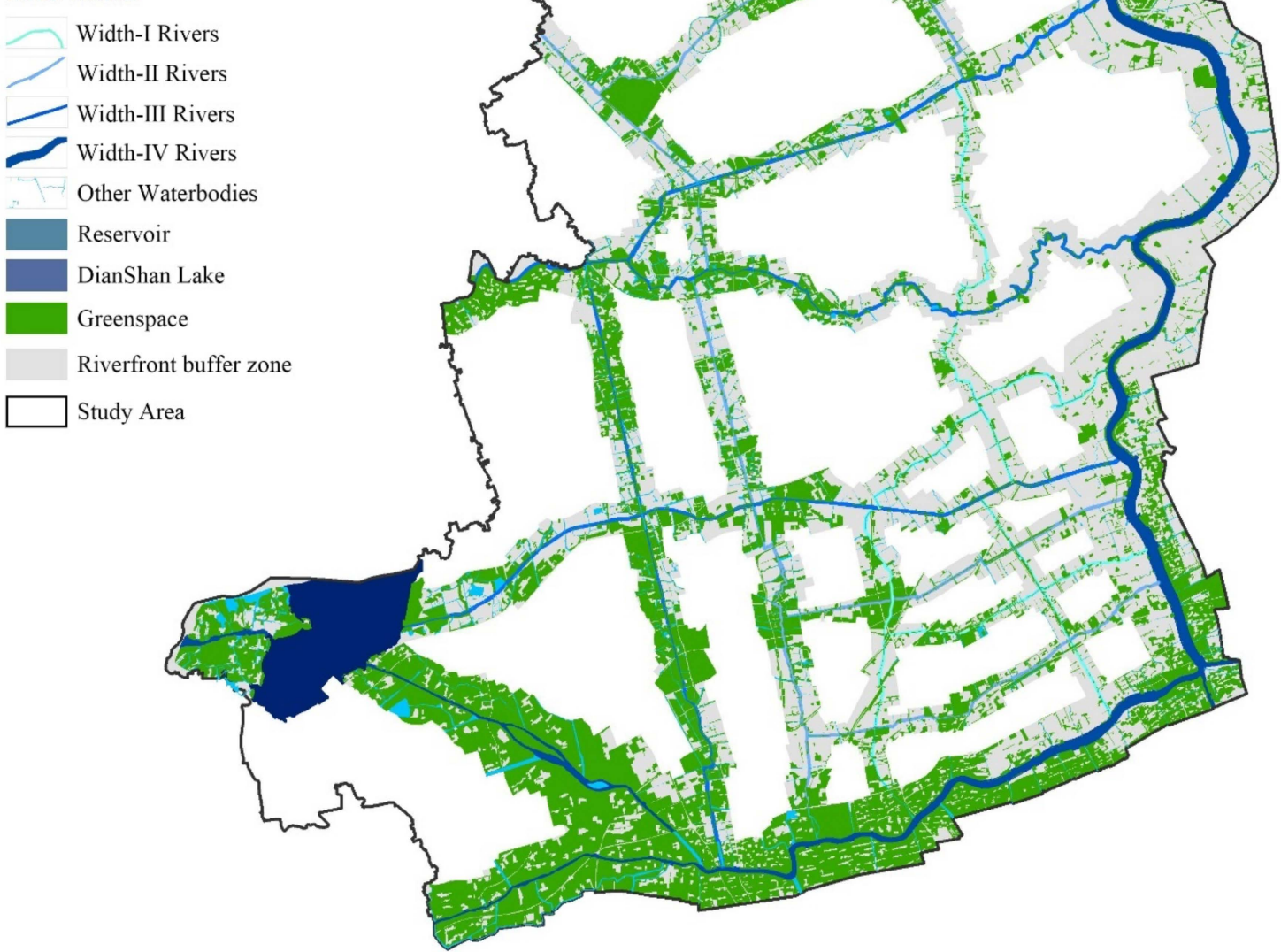

Figure 4. Spatial distribution of blue-green space in the river corridor in the study area.

2.2.4. Quantification of Multi-Dimensional Spatial Impact Factors of Blue-Green Spaces

The cooling effect of the waterfront green space is related to the spatial morphological factors of the green space as well as to the location of the water body and spatial structure between the blue and green space. In this paper, eight indices were used to describe the spatial characteristics of blue-green landscape patterns (Table 1). 
Table 1. Multi-dimensional spatial variables to describe the morphology of waterfront green spaces based on the cooling effect.

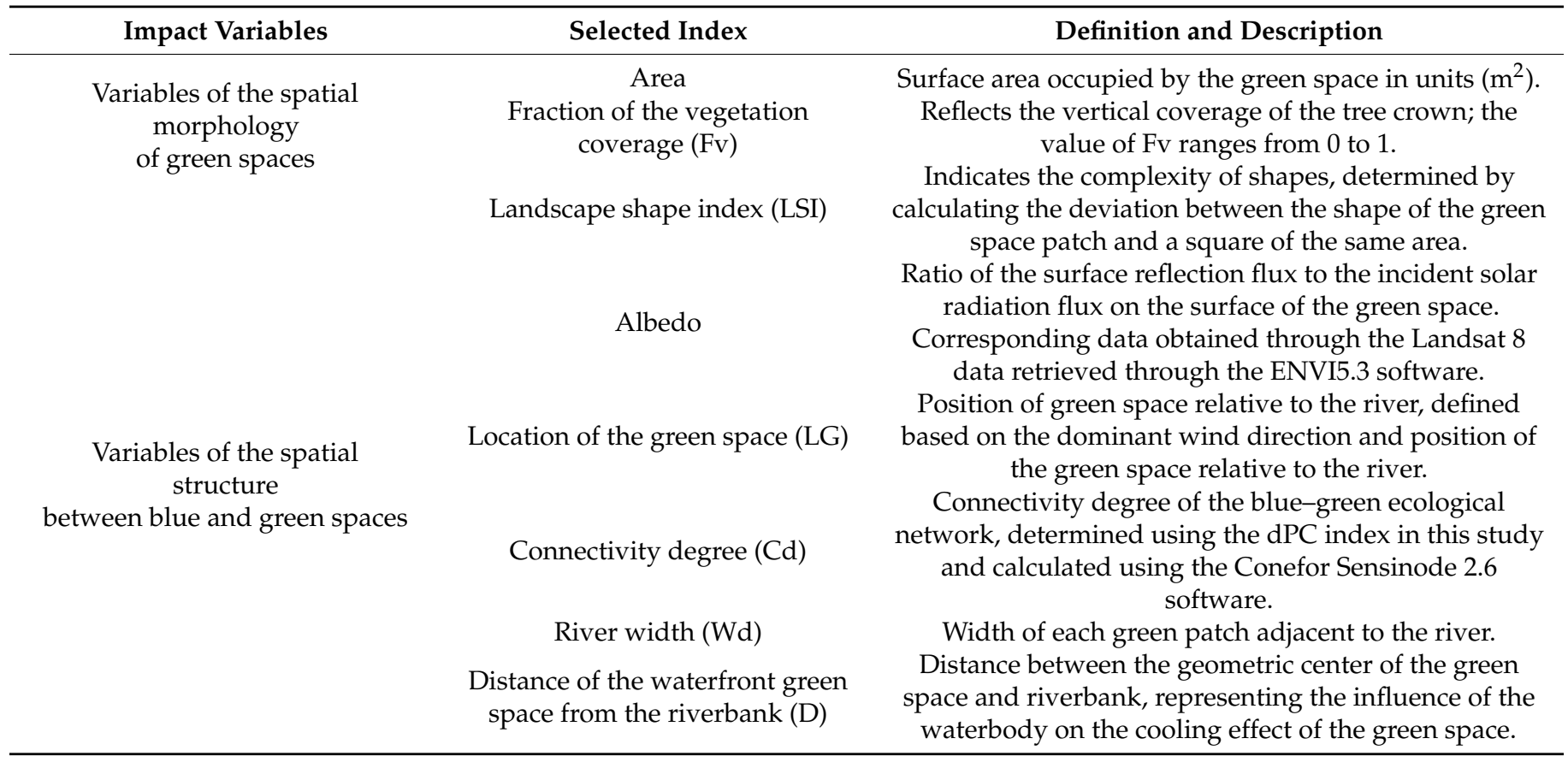

(1) Spatial Morphological Variables

a. Area

The area of the green patches was calculated using the ArcGIS10.4 software platform.

b. Fraction of the vegetation coverage $(\mathrm{Fv})$

Fv describes the greenness of a green space. The value represents the percentage of the vertical projection area of the vegetation (including leaves, stems, and branches) on the ground to the total area of the statistical area and is a key parameter to describe the vegetation coverage on the ground $[62,63] . \mathrm{Fv}$ is the percentage of vegetation reflection in a pixel to the total reflection by decomposition from the interior of a single pixel [64]. The calculation formula is presented as formula (3).

c. Landscape shape index (LSI)

The landscape shape index (LSI) represents the boundary shape of the green space and is determined by calculating the deviation between the shape of a green space patch and a square of the same area [26]. The calculation formula is as follows:

$$
L S I=\frac{0.25 L}{\sqrt{A}}
$$

where $L$ is the total perimeter of the green patch and $A$ is the area of the green patch.

d. Albedo

The surface albedo is the ratio of the surface reflection flux to the incident solar radiation flux on the surface of a green space $[65,66]$. Albedo reflects the comprehensive heat radiation impact of vegetation coverage in green space and the three-dimensional shape of adjacent surrounding environments near green space [48]. In this study, the inversion model for Landsat-TM data, as established by Liang, was applied to retrieve the Landsat 8 data to estimate the surface albedo [67]. The calculation formula is as follows:

$$
\text { Albedo }=0.356 B_{2}+0.130 B_{4}+0.373 B_{5}+0.085 B_{6}+0.072 B_{7}-0.0018
$$

where $B_{2}, B_{4}, B_{5}, B_{6}$, and $B_{7}$ represent the blue, red, near infrared, and both 1 and 2 bands of Landsat 8 data, respectively. 
(2) Spatial Structural Variables

e. Location of the green space (LG)

This variable is defined according to the dominant wind direction to determine the position of green space relative to the river, specifically in the windward or leeward direction of the river.

\section{f. Connectivity degree (Cd)}

The connectivity degree is an effective index to evaluate the continuity of the landscape spatial structure. The decrease in the probability of connectivity (dPC) was selected to evaluate the connectivity degree of the green space in the whole blue-green ecological network to measure the influence of the connectivity of green space [68]. The Conefor Sensinode 2.6 software was used to calculate the dPC value of each green space.

To calculate the dPC values, first, the probability of connectivity (PC) was calculated and the APC values were calculated based on the PC. The calculation formula is presented as formulas (8) and (9):

$$
P C=\frac{\sum_{i=1}^{n} \sum_{j=1}^{n} a_{i} a_{j} P_{i j}{ }^{*}}{A_{L}^{2}}
$$

where $n$ is the total number of green patches and $P_{i j}{ }^{*}$ is the maximum product probability of all possible paths between patches $i$ and $j$ (including the direct dispersal between the two patches). $a_{i}$ and $a_{j}$ are the areas of the habitat at patches $i$ and $j$, respectively, and $A_{L}$ is the total landscape area. The PC values are bounded (ranging from 0 to 1 ) and defined as a probability of coincidence in a manner similar to the degree of coherence [69].

$$
d P C_{k}=\frac{P C-P C_{\text {remove }, k}}{P C} \times 100 \%
$$

where $P C_{\text {remove, }}$ is the overall possible connectivity of the remaining patch after the removal of the ' $k$ ' green patch. $d P C$ measures the importance of the patches in maintaining the landscape connectivity through changes in PC [70].

g. River width (Wd)

This value is the mean course width of each green patch adjacent to the river segment. The value was calculated using the ArcGIS10.4 software. Subsequently, MATLAB 2019 was used to determine the mean width by considering the area and perimeter of each river segment.

h. Distance of the waterfront green space from the riverbank (D)

This value is the smallest geometric distance from the green center to the riverbank. The geometric center point of the green patch was extracted using ArcGIS10.4 [71]. Subsequently, the near analysis tool in ArcGIS10.4 was used to obtain the distance from the river.

\subsubsection{Analysis of the Influence of Spatial Morphological Structure Factors}

(1) Boosted Regression Tree (BRT) model

The boosted regression tree (BRT) model is a machine learning method that combines the advantages of regression and growth models [72]. In terms of output results, the relative influence (or contribution) of each variable is scaled so that the sum is added to 100. The larger the value, the greater the correlation with the dependent variable. The BRT model can also simulate the marginal effect of independent variables and reflect the influence threshold of independent variables on dependent variables in different intervals [73,74]. The BRT model has been widely used to study urban expansion and its influencing factors, and to identify the cold air path and most important predictive variables of cold air path occurrence $[73,75]$. In recent years, the BRT model has also been applied in the context of the urban heat island effect to study the correlation between the urban heat island effect and the influencing factors pertaining to both urban two-dimensional and three-dimensional 
indices, such as the normalized difference vegetation index (NDVI), normalized difference built-up index (NDBI), sky view factors (SVF) and building height [76].

In this study, the BRT model was used to analyze the contribution of the eight structural and morphological variables of waterfront green spaces with the different width classifications of urban rivers to the LST values of green patches. The causal variable was the LST of green patches, and the independent variables were the descriptive spatial variables. The decision tree complexity, learning, rate, and split ratio were 5, 0.01, and 0.5, respectively, and Gaussian data were adopted. This model extracted $50 \%$ of the data points for analysis each time, with $50 \%$ of the data used for training, and 10 -fold cross-validation was performed to estimate the number of optimal trees $[50,75,76]$. The contribution ratios of each factor by BRT regression reflected the importance of independent variables to LST distribution; The marginal effect (ME) changes presented the UCI threshold values and correlation characteristics of each factor.

\section{(2) Criteria for threshold of marginal effect analysis}

The marginal effect (ME) curve between D factor and LST values were used to analyse the affecting rang of synergistic cooling effect of blue-green space. For exploring the important correlation of distance intervel to cooling effect, it is necessary to determine the numerical significance of the following basic criteria and important inflection points of the ME:

a. The inclination of ME curve: The inclination of the ME curve represented the severity of the changes in marginal utility. When the curve took on an ascending trend with great inclination degree, the marginal utility increase was very large; When the curve took on an ascending trend with gradual inclination degree, the marginal utility increase was weak; When the curve inclination was a declining trend, the marginal effect of cooling effect was decrease.

b. The optimal distance of marginal utility: The first inflection point where the inclination degree of the ME curve changed from great ascending trend to gradual ascending trend. It indicated that the marginal utility of synergistic cooling effect of bluegreen space was in the optimal growth state, and the corresponding D value is the optimal distance with the most economic utility of blue-green space to reach the good cooling effect.

c. The maximum distance of marginal utility: This inflection point was the peak values of the marginal effect curve from an ascending trend to a declining trend. It represented the maximum value of the synergistic marginal utility of blue-green space. When the curve was in the gradual ascending range, the marginal utility of waterbody cooling effect declined with the increase of distance, and the ME of green space continues to produce cooling effect. The holistic synergistic cooling effect of riverfront blue-green space increased slowly and reached the maximum cooling effect at the inflection point.

d. The threshold distance of cooling effect: The ME curve showed a declining trend, and after it declined to the lowest value, the curve appeared irregular alteration. This inflection of the lowest value represented the longest distance of the blue-green synergistic cooling effect. The declining interval of ME curve presented the ME attenuation of cooling effect from both blue space and green space. The position of the lowest attenuation value of the curve was no longer affected by the distance from the synergistic ME of blue-green spaces, namely, the threshold distance of the blue-green synergistic cooling effect was identified.

(3) Classification of spatial morphological group types (MG types) and correlation analysis for the LST

The impact of the spatial factors of a waterfront green space on the LST is a comprehensive effect. The different intervals of a single spatial independent variable usually lead to significant spatial differentiations of the causal variable LST. A single spatial variable can be graded by the corresponding LST influence change interval and multiple spatial independent variables can be composed as well as constituted as by certain MG types, which 
are grouped by the basic grade elements of single factors in every possible combination to describe the classification of green patches with certain spatial three-dimensional characteristics. Different three-dimensional characteristics of green patches produce corresponding differences in the LST distribution. This kind of partitioning of the MG types to describe the morphology composition of green space can clearly reflect the cooling effect of green space types in terms of the spatial and morphological characteristics. This key innovation distinguishes our study from the existing research.

The four key factors affecting the LST, namely the area, FV, Cd, and LG, were used to construct the morphological group (MG) types. Considering that the threshold cooling distances of different width grades of rivers are different and to reduce the interference of specific surrounding environmental factors in the study area far from the rivers, the distribution data of the waterfront green space at a distance of $200 \mathrm{~m}$ from the riverbank were selected to identify the great cooling effect correlation between the MG types and LST values.

The classification method of MG types and the analysis process of the correlation characteristics between MG types and LST were as follows:

a. The grade level of a single spatial variable was classified (Table 2). Each spatial variable was assigned different grade levels. The value interval was identified based on the effect of the variables on the spatial differentiation interval of the LST values.

b. The MG types were grouped. A subcategory of each factor was randomly combined to form MG types with different structural and morphological characteristics. The specific combinational logic and type delimitations are illustrated in Figure 5.

Table 2. Value interval and meaning of subcategories of green space morphological factors.

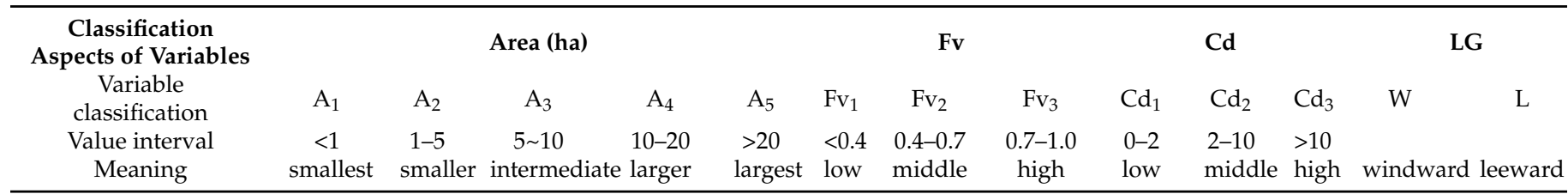

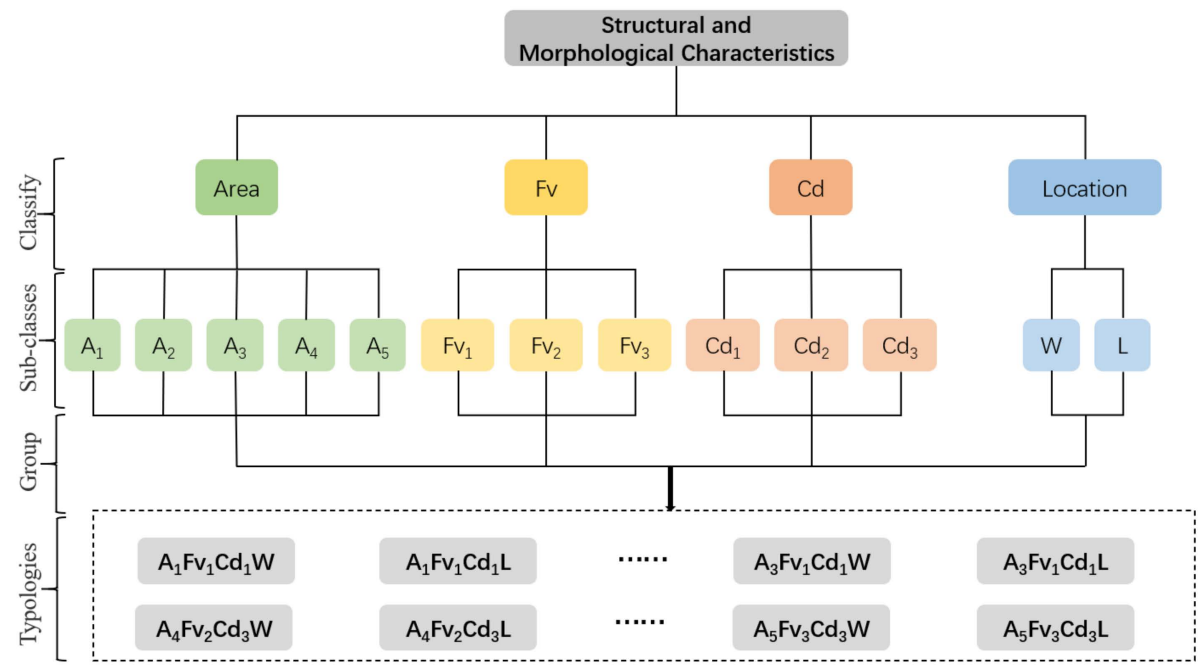

Figure 5. Logical division and classification of green space morphological types.

c. The correlation characteristics between the MG types with great cooling effects and LST values were identified. The temperature standard of highly suitable green spaces was considered to reflect the residents' general body temperature that can meet the survival needs of residents. The standard of high-temperature heat waves determined by the Chinese government involves a maximum daily temperature of $35^{\circ} \mathrm{C}$ as the limit for green space cooling optimization. The results show that in August, the 
difference between the LST and air temperature is approximately $1.8^{\circ} \mathrm{C}$ [77]. In this study, the data group with an LST lower than $36.8^{\circ} \mathrm{C}$ was selected. According to the increasing sequence of the LST, the correlation characteristics between different $\mathrm{Mg}$ types and LST were analyzed by observing the classification of the spatial composition of the corresponding MG types.

\section{Results}

3.1. Width-I Rivers $(20-30 \mathrm{~m})$

3.1.1. Contribution of Each Spatial Variable to the LST

The contribution ratios of various impact factors of the green space to the LST were calculated in the buffer zone of Width-I rivers by using the BRT model (Figure 6). Fv $(43.5 \%)$, area $(24.0 \%)$, D $(12.30 \%)$, LSI $(6.5 \%)$, and Cd $(6.1 \%)$ were noted to be the most important impact variables. The Fv, area, and LSI were used to describe the morphology of green space. For Width-I rivers, the composition and shape of the green space were the dominant factors. Specifically, the total contribution ratio of the Fv and area was as high as $67.50 \%$, which indicated that large-scale vegetation coverage had a significant impact. The contribution of D to LST was notable, as well, with a contribution ratio of $12.3 \%$. The contribution ratios of the other factors were extremely low and LG exerted the smallest influence $(0.4 \%)$.

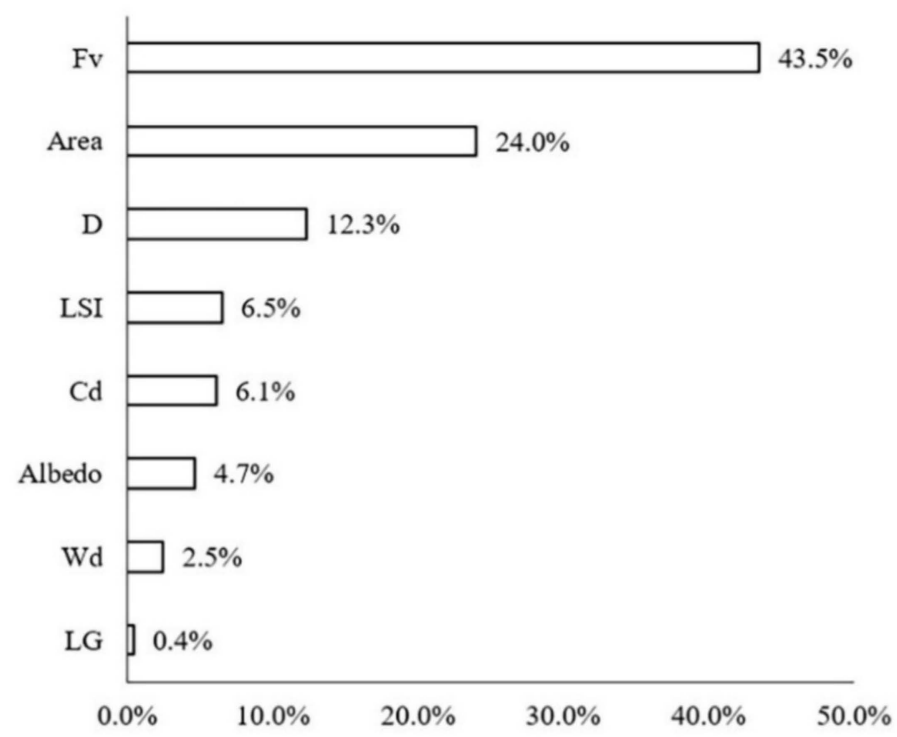

Figure 6. Contribution ratios of each spatial variable to the LST in Width-I river corridors.

3.1.2. Relationship between D (Distance of the Waterfront Green Space from the Riverbank) and LST Values

The LST data distribution of the waterfront green space in Width-I rivers was considerably affected by the $\mathrm{D}$ values (Figure 7). The marginal effect (ME) curve obtained by the BRT model showed that (1) when D was less than $250 \mathrm{~m}$, the inclination of the marginal effect (ME) curve changed significantly, while the inflection point at $250 \mathrm{~m}$ represented the distance with the most economically marginal effect. In other words, the UGCI located within $250 \mathrm{~m}$ strengthened the WCI effect, resulting in the best combination of the synergistic cooling effect. The curve inclination was large, which illustrated that the interaction between the two cold islands was significant. (2) When the D ranged from 250 to $400 \mathrm{~m}$ with increasing distance, the cooling effect intensity of the waterbody decreased and the synergistic cooling effect of the blue-green space gradually increased, with the total effect maximized at $400 \mathrm{~m}$. (3) When D was between 400 and $600 \mathrm{~m}$, the inclination of the ME curve decreased, indicating that the influence of the WCI had reduced. The ME was the 
lowest at $600 \mathrm{~m}$, which was identified as the threshold distance of blue-green synergistic cooling in the Width-I river zone.

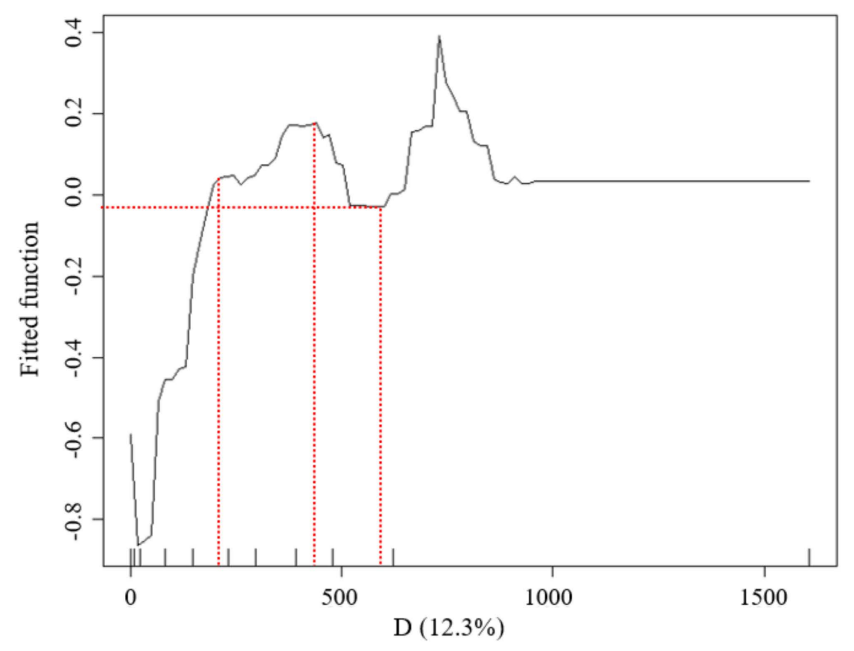

Figure 7. Relationship between the D factors and LST of the waterfront green space in the buffer zone of Width-I river corridors.

\subsubsection{Morphological Group (MG) Types and LST Values}

The MG types with LST values lower than $36.8^{\circ} \mathrm{C}$ were observed and sorted according to the increasing sequence of LST values. Most of the MG types with low LST values corresponded to high levels of $\mathrm{Fv}$ and A (Figure 8). Width-I rivers corresponded to the least number of ME types with LSTs below $36.8^{\circ} \mathrm{C}$, which indicated a certain influence of the river width. For values lower than $35.5^{\circ} \mathrm{C}$, the variation degree was notable and the LST changed considerably with the MG types. The MG types of $\mathrm{Fv}_{3}$ and $\mathrm{A}_{5}$ had the lowest LST. For these MG types, the influence of the Fv factor was greater than that of the area. For ME types with the same $\mathrm{Fv}$ and area classifications, a higher $\mathrm{Cd}$ grade corresponded to a lower relative LST temperature. The cooling effect of the MG types in leeward locations was generally higher than that of the MG types in windward locations.

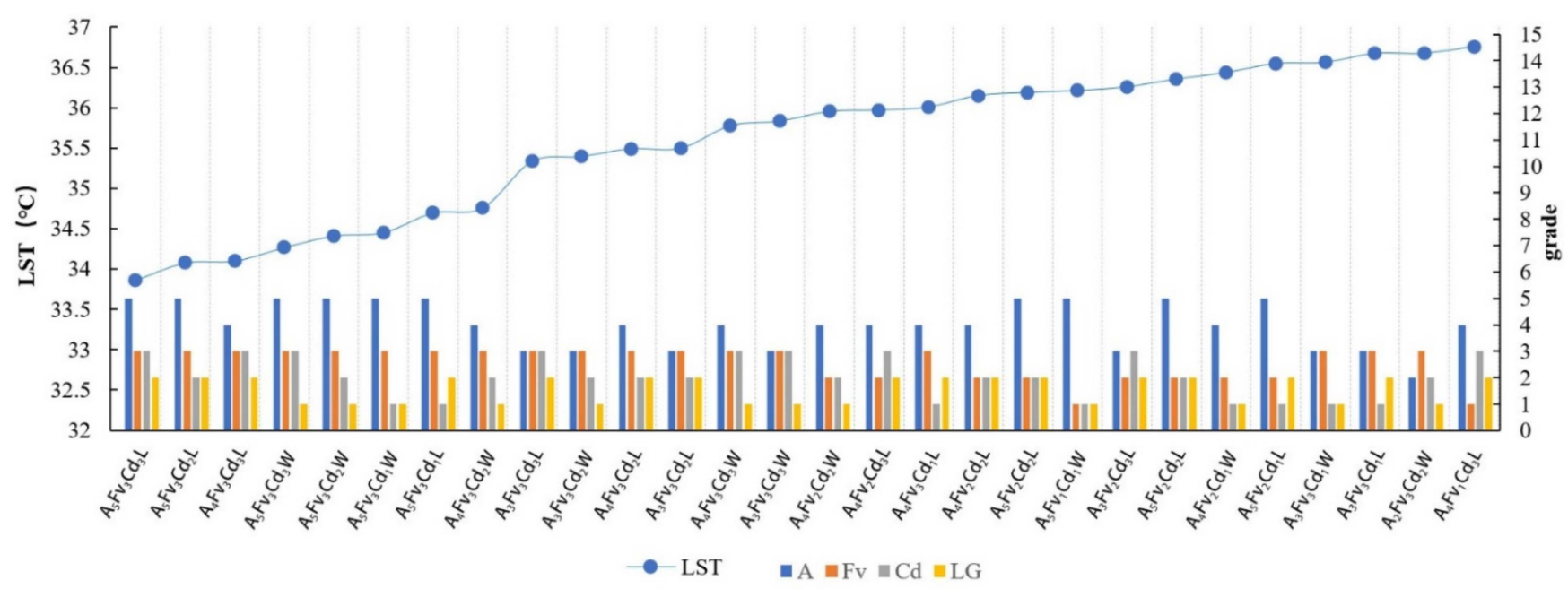

Figure 8. Sorted MG types with LST values lower than $36.8^{\circ} \mathrm{C}$ in the Width-I river buffer zone and the linear correlation between the MG types and their LST values.

According to the 81 groups of MG-type data in the $200 \mathrm{~m}$ range from the riverbank, with a strong cooling influence zone, the change characteristics of the LST values for 
the ME types in different locations (leeward or windward) were analyzed according to the increasing LST. In the leeward zone, the MG types usually exhibited low LST values and evident differences were observed between the $\mathrm{L}$ and $\mathrm{W}$ locations (Figure 9a). The mean temperatures for the leeward and windward MG types were $37.11^{\circ} \mathrm{C}$ and $37.57^{\circ} \mathrm{C}$, respectively. The ascending order of the corresponding LST values of MG types with Cd levels indicated that the green space with higher-grade Cd usually exhibited lower LST values compared to those of lower-grade $\mathrm{Cd}$ (Figure $9 \mathrm{~b}$ ). The mean LSTs of $\mathrm{Cd}_{1}, \mathrm{Cd}_{2}$, and $\mathrm{Cd}_{3}$ were approximately $37.59^{\circ} \mathrm{C}, 37.28^{\circ} \mathrm{C}$, and $37.36{ }^{\circ} \mathrm{C}$, respectively.

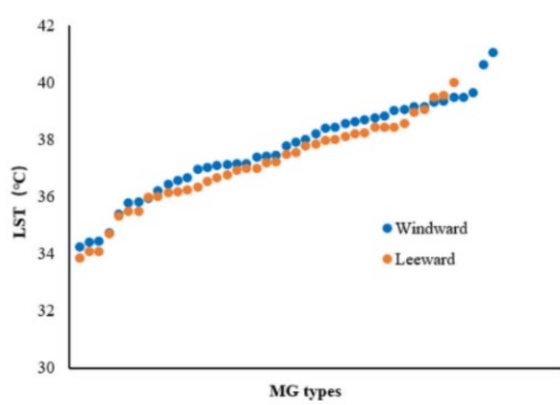

(a)

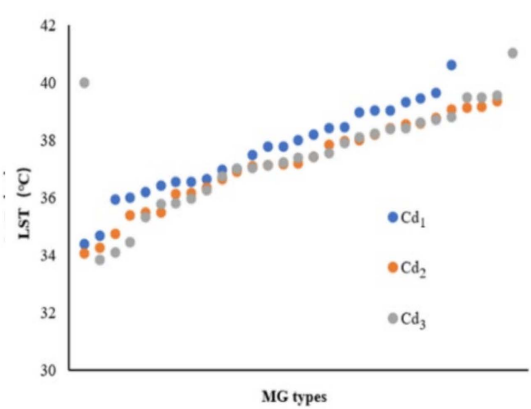

(b)

Figure 9. (a) Scatter plot of LST values corresponding to the MG types of green space in different locations (leeward or windward) in the Width-I river zone according to the increasing LST. (b) LST values corresponding to the MG types of green space in different $\mathrm{Cd}$ grades in the Width-I river zone according to the increasing LST.

\subsection{Width-II Rivers (30-50 m)}

\subsubsection{Contribution of Each Spatial Variable to the LST}

The contribution ratios of the green space factors in the buffer zone of the WidthII rivers to the LST changed more notably than those of the Width-I rivers (Figure 10). Although the factor that most notably influenced the LST values was Fv (34.1\%), followed by A $(29.7 \%)$, the importance of the river width increased and it emerged as the third most-notable influencing factor, with a contribution ratio of $11.8 \%$. Furthermore, D and $\mathrm{Cd}$ notably influenced the LST and their contribution ratios reached $8.2 \%$.

\subsubsection{Factors and LST Values}

The LST data distribution of the waterfront green space in the Width-II river zone was highly influenced by the $\mathrm{D}$ values (Figure 11). With the increasing river width, the cooling effect of the green space was observed over larger distances. When $\mathrm{D}$ was less than $205 \mathrm{~m}$, the inclination of the marginal effect (ME) curve was large and a considerable synergistic cooling island effect was observed between the waterbody and the green space. The inflection point at $205 \mathrm{~m}$ represented the D with most economically marginal effect; when D was between 205 and $765 \mathrm{~m}$, the ME of the blue-green synergistic cooling island effect increased slowly and reached a maximum value at $765 \mathrm{~m}$. When $\mathrm{D}$ was between 765 and $900 \mathrm{~m}$, the inclination tendency of the ME curve decreased. Additionally, the value was minimized at $900 \mathrm{~m}$, which was the threshold distance of blue-green synergistic cooling in the width-II river zone. When D was greater than $900 \mathrm{~m}$, the WCI from the rivers did not affect the surrounding environment and the UGCI from the green space was dominant. 


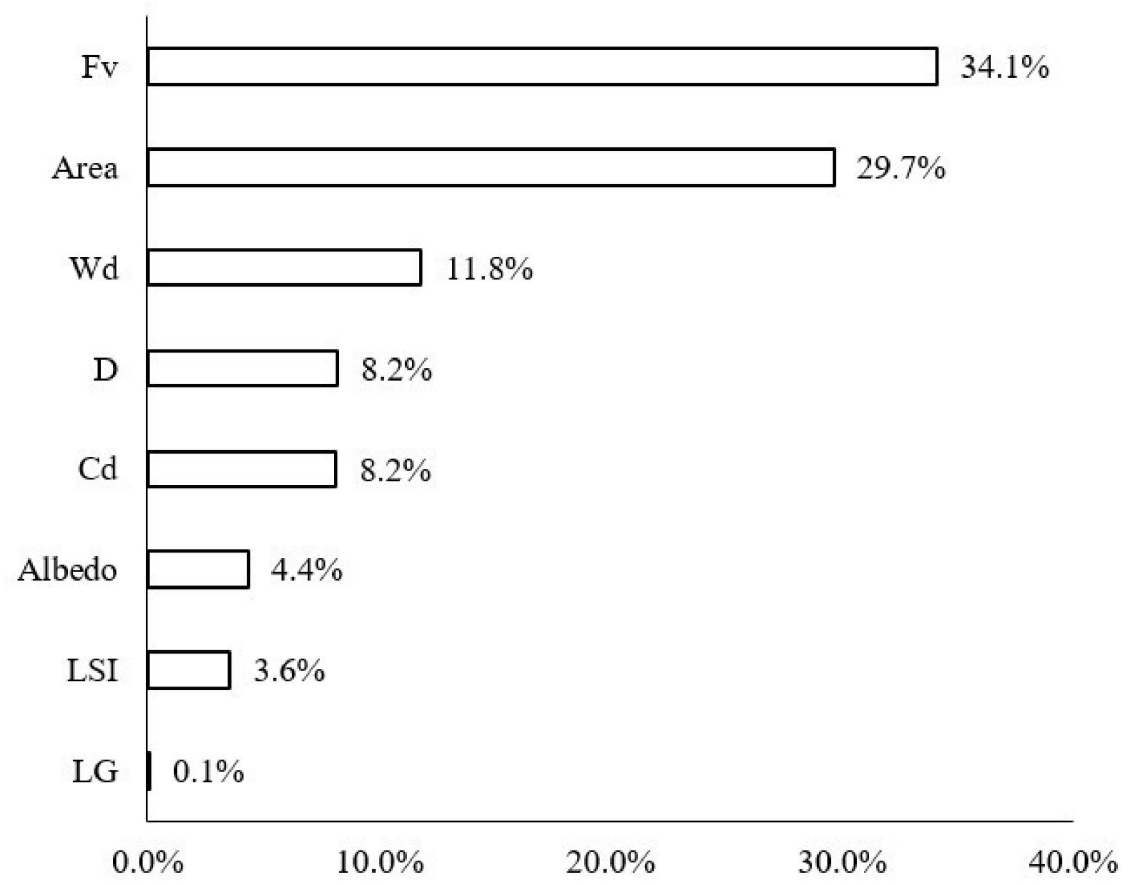

Figure 10. Contribution ratios of each factor to the LST of the waterfront green space in Width-II river corridors.

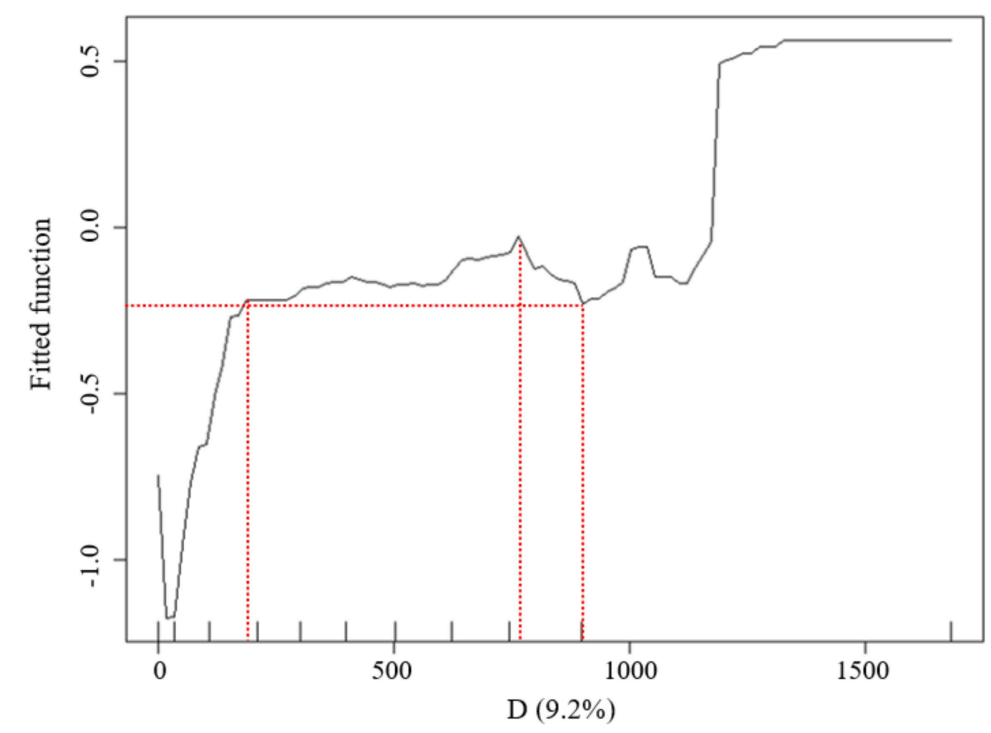

Figure 11. Relationship between the D factors and LST of the waterfront green space in the buffer zone of Width-II river corridors.

\subsubsection{MG Types and LST Values}

For Width-II rivers, the numbers of ME types corresponding to LST below $36.8{ }^{\circ} \mathrm{C}$ increased and the change in the LST value of each MG type was more gradual than that of Width-I (Figure 12). The Fv and area factors remained the dominant factors. The MG types with high-grade levels of Fv and area factors exhibited low LST values. The LST variation gradient of the MG types was relatively larger under values lower than $35.5^{\circ} \mathrm{C}$, although the variation range of the LST was narrower than that for the Width-I rivers. The effect of the Cd factor on the LST was enhanced and the MG type of green space with a low LST exhibited a high connectivity. 


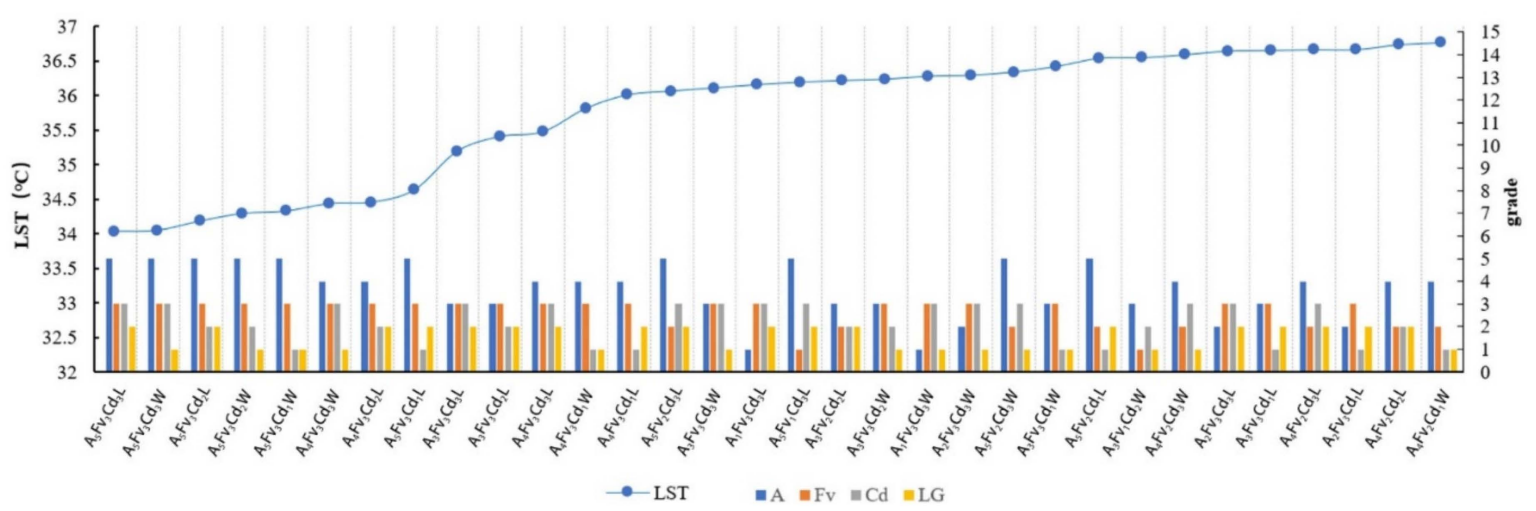

Figure 12. Sorted MG types with LST values lower than $36.8^{\circ} \mathrm{C}$ in the Width-II river buffer zone and the linear correlation between the MG types and their LST values.

Based on the LST data of the MG types located $200 \mathrm{~m}$ from the riverbank with a strong cooling influence zone, the variation in the LST value of the ME types in different locations (leeward or windward) was analyzed. The MG types located in the L-direction exhibited low LST values and the LST differences for the MG types in both the leeward and windward directions were smaller than those of the LST values for the corresponding Width-I cases (Figure 13a). The mean LSTs of the MG types in the leeward and windward directions were $37.25{ }^{\circ} \mathrm{C}$ and $37.45^{\circ} \mathrm{C}$, respectively. Notable differences were observed in the LST values among the ME types with three Cd levels. The MG types of green spaces with lower-grade $\mathrm{Cd}$ exhibited lower LST values (Figure 13b). The mean LSTs of $\mathrm{Cd}_{1}, \mathrm{Cd}_{2}$, and $\mathrm{Cd}_{3}$ were $37.67^{\circ} \mathrm{C}, 37.37^{\circ} \mathrm{C}$, and $37.08^{\circ} \mathrm{C}$, respectively.

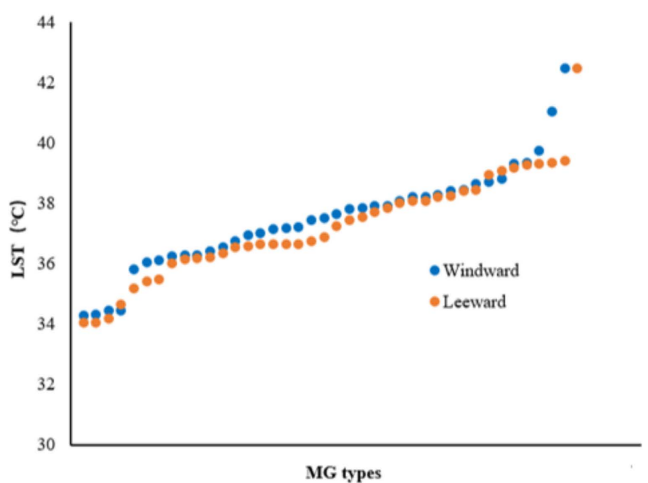

(a)

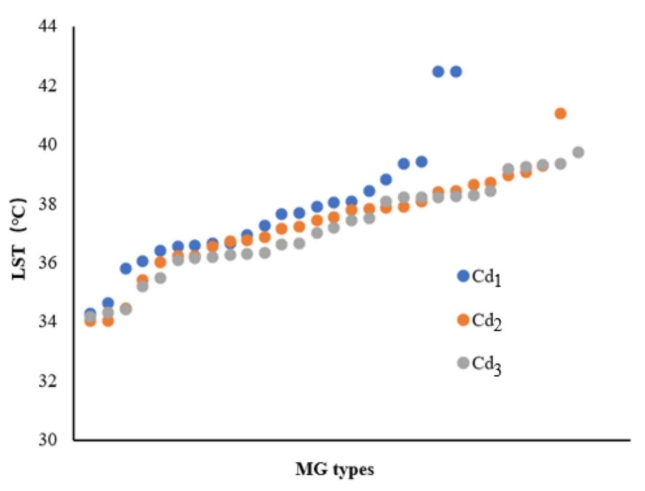

(b)

Figure 13. (a) Scatter plot of LST values corresponding to the MG types of green space in different locations (leeward or windward) in the Width-II river zone according to the increasing LST. (b) LST values corresponding to the MG types of the green space with different Cd grades in the Width-II river zone according to the increasing LST.

\subsection{Width-III Rivers $(30-50 \mathrm{~m})$}

\subsubsection{Contribution of Each Spatial Variable to the LST}

The contribution of each impact factor to the LST in the waterfront buffer zone of the Width-III rivers was consistent with that of the Width-II rivers (Figure 14). FV, area, $\mathrm{Wd}, \mathrm{D}$, and Cd remained the dominant factors. The influence of three of these factors, i.e., FV, area, and $\mathrm{Wd}$, was significant, with contribution rates of $39.5 \%, 27.6 \%$, and $9.6 \%$, respectively. With the increase in the river width, the trend was different from that of the Width-II rivers: the D variable was the fourth most-important factor influencing the LST, with its contribution ratio slightly increased to $9.2 \%$. The importance of $\mathrm{Cd}$ decreased to $5.1 \%$ and the effects of the albedo, LSI, and LG were small but relatively stable. 


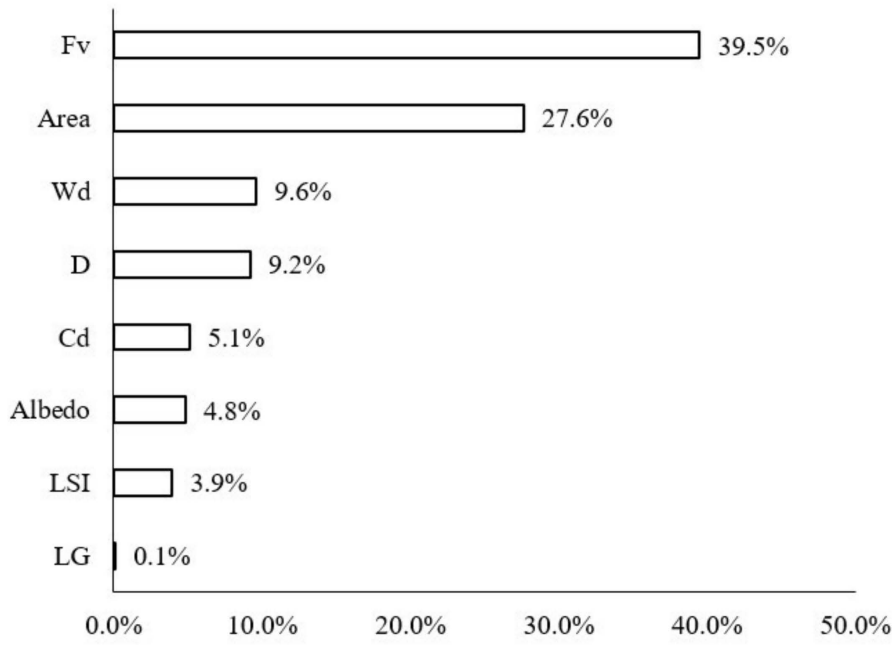

Figure 14. Contribution ratios of each factor to the LST of the waterfront green space of Width-III river corridors.

\subsubsection{Factors and LST Values}

The LST data distribution of the waterfront green space in the Width-III river zone was more highly influenced by the distance from the riverbank than that of the WidthII rivers (Figure 15). According to the change in the curve inclination, when D was less than $260 \mathrm{~m}$, the inclination of the marginal effect (ME) curve was large. Namely, with increasing distance, the cooling effect intensity of the waterbody and green space increased significantly and a great synergistic cooling island effect was observed between the waterbody and the green space. The $\mathrm{D}$ with the most economically marginal effect of blue-green synergistic cooling was $260 \mathrm{~m}$; when D was between 260 and $630 \mathrm{~m}$, the ME of the cooling effect of the blue-green space increased slowly and reached a maximum value at $630 \mathrm{~m}$. When D was between 630 and $1200 \mathrm{~m}$, the inclination tendency of the ME curve decreased. The lowest value at $1200 \mathrm{~m}$ was the threshold distance of blue-green synergistic cooling in the Width-III river zone.

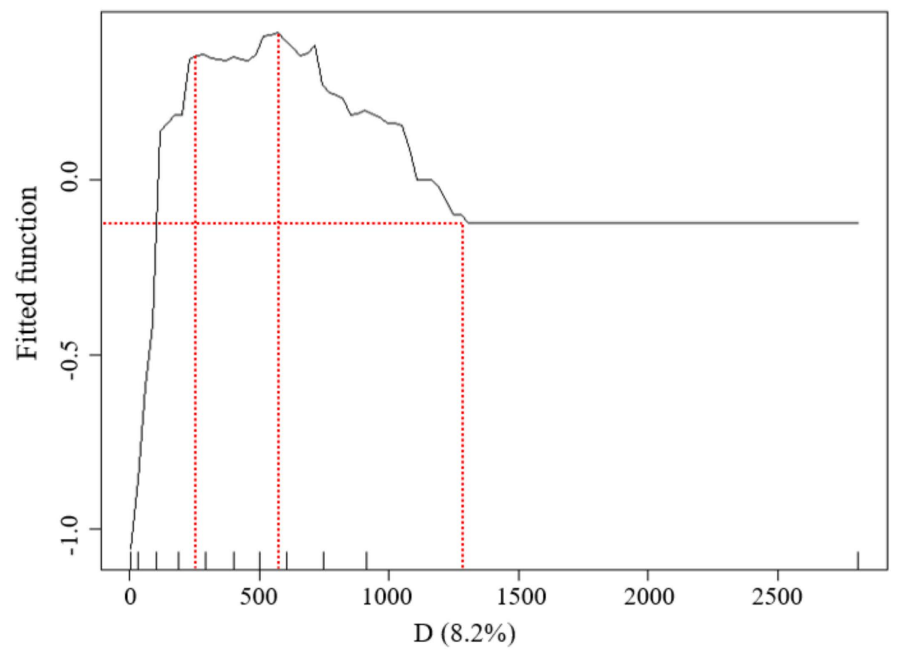

Figure 15. Relationship between the D factors and LST of the waterfront green space in the buffer zone of Width-III river corridors.

\subsubsection{MG Types and LST Values}

For Width-III rivers, the numbers of ME types corresponding to LST values below $36.8^{\circ} \mathrm{C}$ increased and the gradient changes of the LST values corresponding to each MG type were gentler than those of Width-II rivers (Figure 16). With the aggravation of WCI 
from the rivers, ME types with lower area-grades existed in the low-value range of the LST. The Fv factor was a notable influencing factor, with high Fv-grade MG-types exhibiting considerably low LST values. The numbers of ME types with LST values below $35.5^{\circ} \mathrm{C}$ increased significantly and the proportion of ME types in the low LST range (LST below $35.5^{\circ} \mathrm{C}$ ) accounted for $30.56 \%$ of the total value range (LST below $36.8^{\circ} \mathrm{C}$ ). In particular, more MG types of green space existed with extremely low LST values. However, the LST change gradient was small and the LST did not change considerably between the different MG types. The effect of the Cd factor on the LST decreased.

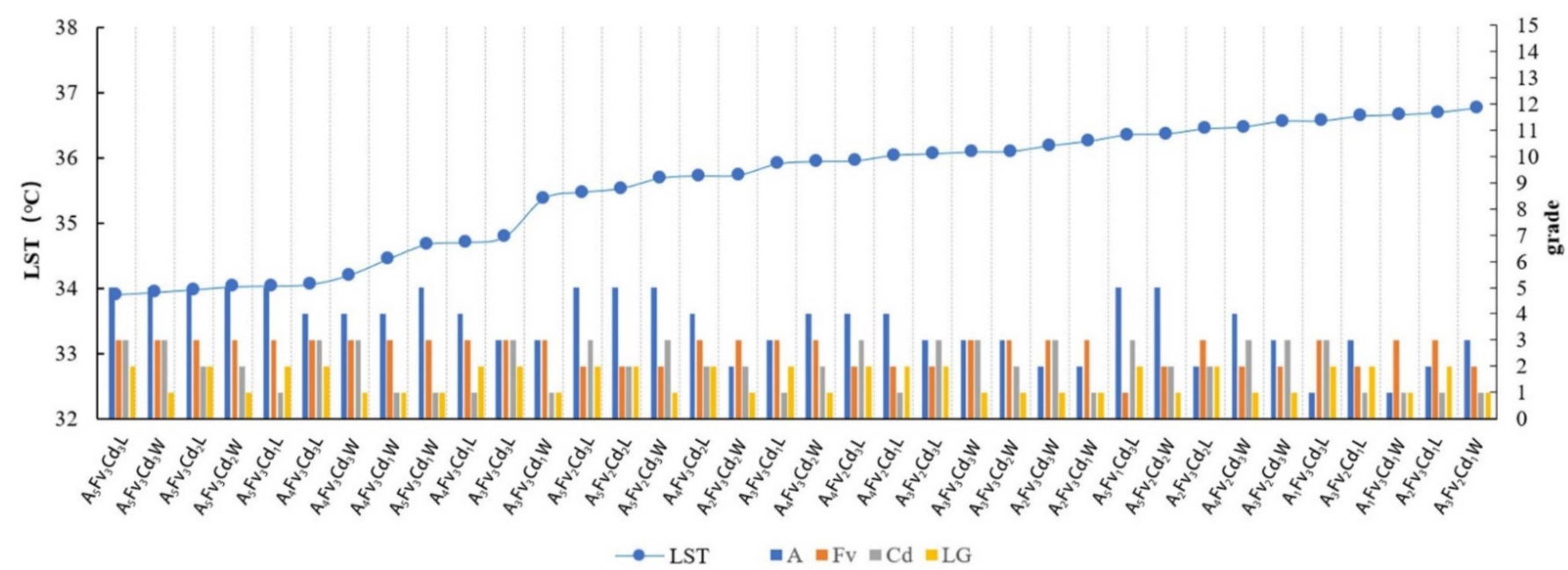

Figure 16. Sorted MG types with LST values lower than $36.8^{\circ} \mathrm{C}$ in the Width-III river buffer zone and the linear correlation between the MG types and their LST values.

According to the LST data of the MG types impacted by a strong cooling distance of $200 \mathrm{~m}$ from the riverbank, the influence of the WCI in the Width-III river zone was strengthened and the LST values of most MG types were lower than those for the previous river-width level. The value of the MG types in the leeward area was lower than that in the windward area. The differences in the LST values between the windward and leeward locations were extremely small on both sides of the Width-III rivers (Figure 17a). The mean LST values of the MG types in the leeward and windward locations were $36.91{ }^{\circ} \mathrm{C}$ and $37.01{ }^{\circ} \mathrm{C}$, respectively. A negative correlation was observed between the $\mathrm{Cd}$ and LST, although the LST differences among the ME types of the three $\mathrm{Cd}$ levels were not obvious (Figure $17 \mathrm{~b}$ ). The mean LSTs of $\mathrm{Cd}_{1}, \mathrm{Cd}_{2}$, and $\mathrm{Cd}_{3}$ were $37.21^{\circ} \mathrm{C}, 36.93{ }^{\circ} \mathrm{C}$, and $36.73{ }^{\circ} \mathrm{C}$, respectively.

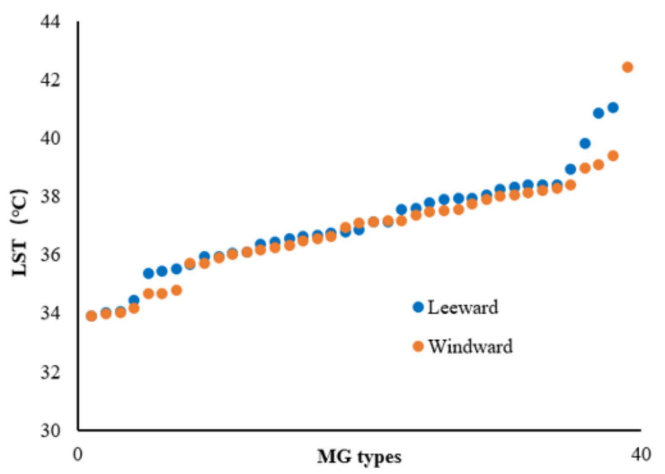

(a)

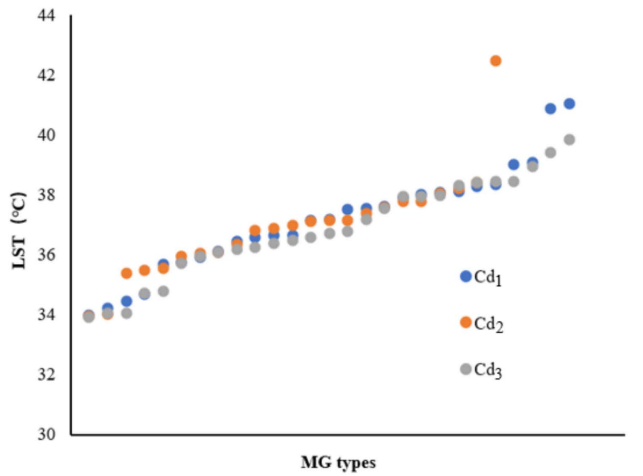

(b)

Figure 17. (a) Scatter plot of the LST values corresponding to the MG types of green space in different locations (leeward or windward) in the Width-III river zone according to the increasing LST. (b) LST values corresponding to the MG types of green space with different Cd grades in the Width-III river zone according to the increasing LST. 


\subsection{Width-IV Rivers (Width of More than $100 \mathrm{~m}$ )}

\subsubsection{Contribution of Each Spatial Variable to the LST}

The contribution of each impact factor to the LST in the waterfront buffer zone of the Width-IV rivers was consistent with that of the Width-II rivers (Figure 18). Fv, area, and $\mathrm{Wd}$ were the dominant factors influencing the LST. The contribution ratios of $\mathrm{Fv}$, area, and WD were $41.2 \%, 26.2 \%$, and $17.2 \%$, respectively. The sum ratio of the three main spatial factors for cooling was approximately $85 \%$. In particular, the proportion of the effect of $\mathrm{Wd}$ increased to $17.2 \%$. The importance of D factors on the LST values of the waterfront green space was reduced by $4.6 \%$ due to the large range of cooling effects for these rivers.

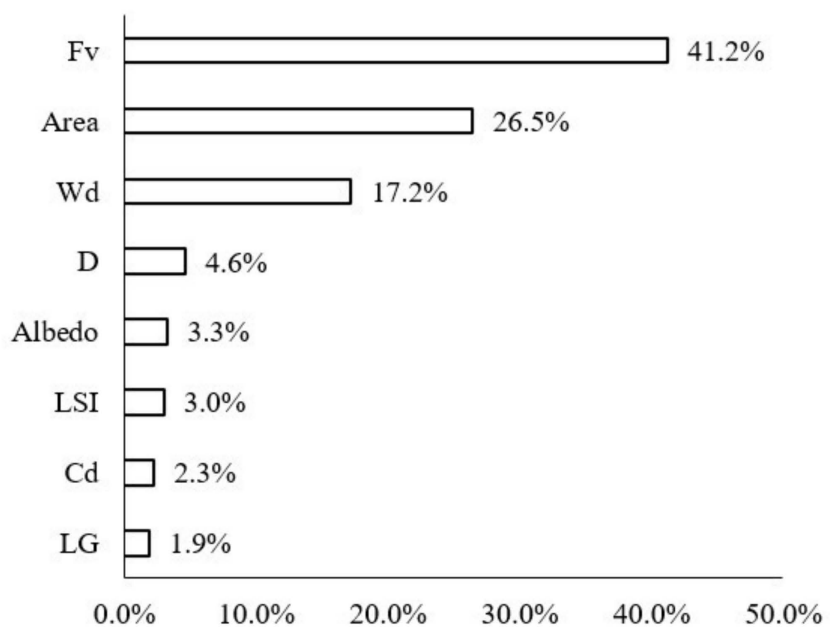

Figure 18. Contribution ratios of each factor to the LST of the waterfront green space of Width-IV river zones.

\subsubsection{Factors and LST Values}

In the Width-IV river zone, the effect of the Wd factor was the highest (Figure 19). According to the inclination changes in the ME curve, when D was less than $250 \mathrm{~m}$, a notable synergistic cooling island effect was observed between the waterbody and green space. When D was between 250 and $1030 \mathrm{~m}$, the ME of the blue-green synergistic cooling island effect increased gradually and reached a maximum value at $1030 \mathrm{~m}$. When D was between 1030 and $1395 \mathrm{~m}$, the ME between D and LST decreased, reaching the lowest value at $1395 \mathrm{~m}$. Namely, the threshold distance of the blue-green synergistic cooling in the Width-IV river zone was $1395 \mathrm{~m}$. When D was more than $1395 \mathrm{~m}$, the LST values increased mainly through the cooling effect of the green space.

\subsubsection{MG Types and LST Values}

The amplification of the LST values was the gentlest in the case of the Width-IV rivers and the data of the MG types corresponding to LST values lower than $36.8^{\circ} \mathrm{C}$ were selected (Figure 20). The Width-IV zone involved a certain amount of cultivated land that included the waterfront green space, which weakened the cooling effect related to the area factor. As the river width increased, the WCI intensified, resulting in the lower LST of the MG types in the waterfront green space. The Fv factor was significant and the highest $\mathrm{Fv}$ grade corresponded to the main body of the MG types with LST values lower than $36.8^{\circ} \mathrm{C}$. The numbers of $\mathrm{MG}$ types with values below $35.5^{\circ} \mathrm{C}$ were particularly large and the proportion of MG types in the low LST value section (with the LST smaller than $35.5^{\circ} \mathrm{C}$ ) accounted for $50 \%$ of the total LST value section (with the LST smaller than $36.8^{\circ} \mathrm{C}$ ). Specifically, half of the MG types of the green space exhibited an extremely low LST. The LST variation gradient of the MG types was relatively small. The different $\mathrm{Cd}$ grades did not significantly influence the LST temperature. 


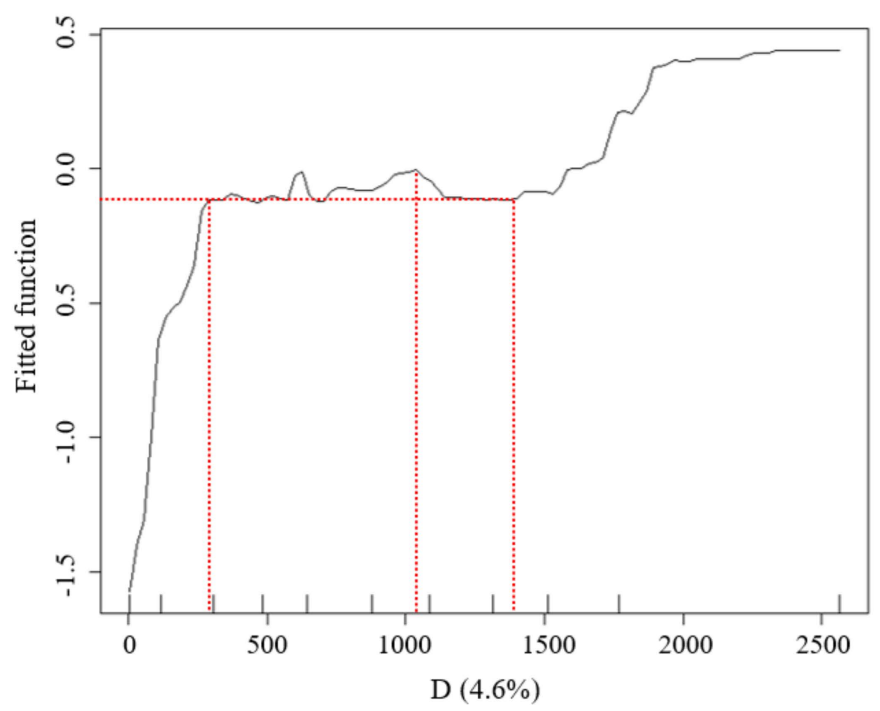

Figure 19. Relationship between the D factors and LST of the waterfront green space in the buffer zone of Width-IV river corridors.

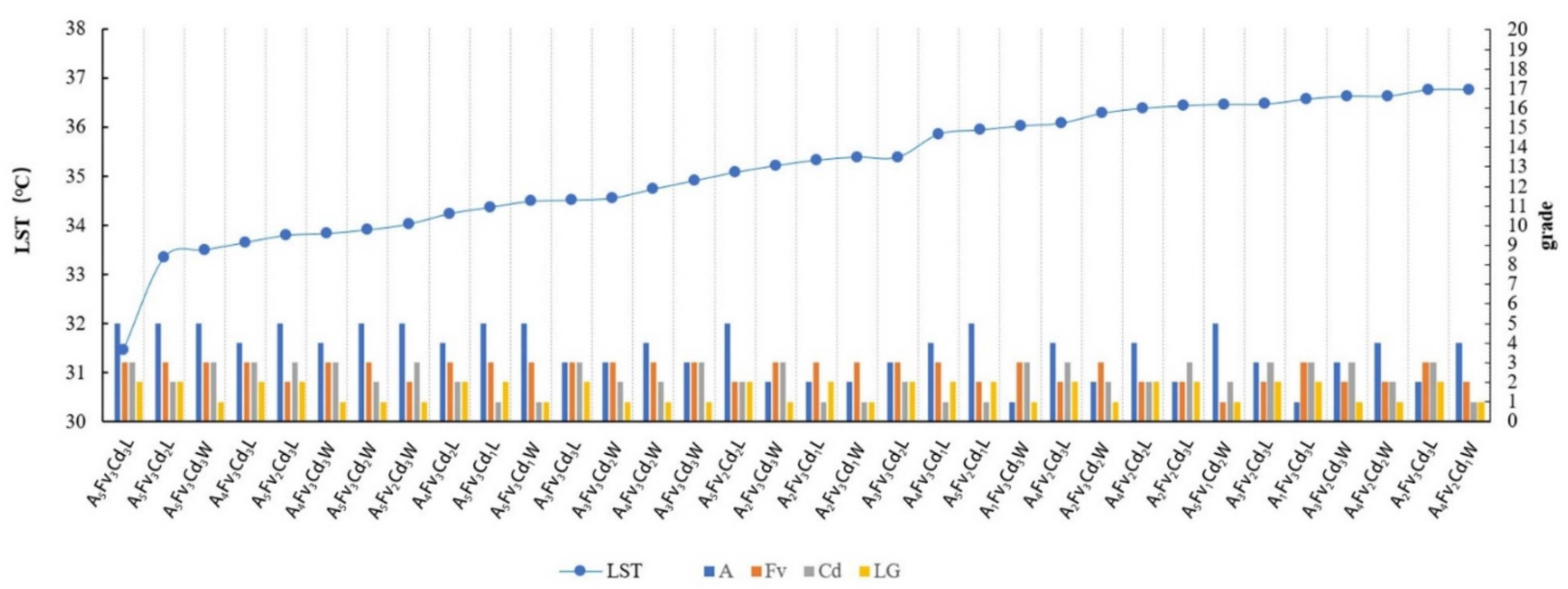

Figure 20. Sorted MG types with LST values lower than the $36.8^{\circ} \mathrm{C}$ Width-IV river buffer zone and the linear correlation between the MG types and their LST values.

According to the LST data of the MG types in the $200 \mathrm{~m}$ range from the riverbank, with a strong cooling influence zone, the influence of the Width-IV rivers was significant in general and the LST of most MG types was lower than that of the previous three grades of river widths. The LST values of the MG types in the L-location were lower than those in the $\mathrm{W}$ location and the difference between them was notable (Figure 21a). The mean LSTs of the MG types in the leeward and windward directions were $36.67^{\circ} \mathrm{C}$ and $37.01^{\circ} \mathrm{C}$, respectively. Compared to the LST corresponding to the MG types of the three Cd grades, high Cd values and a low LST distribution correlation were observed among the ME types, and the LST differences for $\mathrm{Cd}_{1}, \mathrm{Cd}_{2}$, and $\mathrm{Cd}_{3}$ were significant (Figure 21b). The mean LSTs for $\mathrm{Cd}_{1}, \mathrm{Cd}_{2}$, and $\mathrm{Cd}_{3}$ were $37.37^{\circ} \mathrm{C}, 36.85^{\circ} \mathrm{C}$, and $36.41^{\circ} \mathrm{C}$, respectively. 


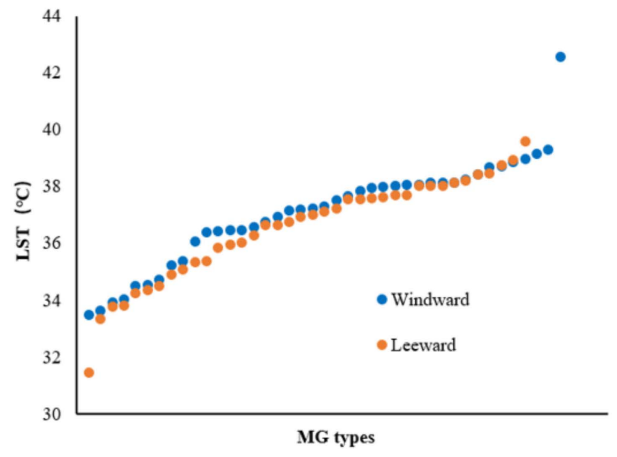

(a)

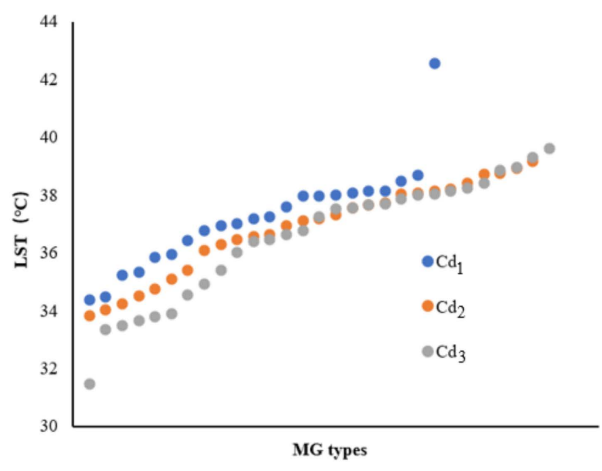

(b)

Figure 21. (a) Scatter plot of LST values corresponding to the MG types of green space in different locations (leeward or windward) in the Width-IV river zone according to the increasing LST. (b) LST values corresponding to the MG types of the green space with different Cd grades in the Width-IV river zone according to the increasing LST.

\section{Discussion}

\subsection{Difference in the Cooling Effect of the River Width Scale}

The contribution ratios of the Wd factor to the LST were $2.5 \%$ (width-I), $11.8 \%$ (widthII), 9.6\% (width-III), and $17.2 \%$ (width-III) according to the BRT model analysis. Based on the importance order of the impact between Wd and LST factors, the importance of $\mathrm{Wd}$ was not significant for river widths below $30 \mathrm{~m}$. For rivers with a width of more than $30 \mathrm{~m}$, the contribution of Wd was significant (Figure 22). According to the curve analysis of the relationship between the impact distance of $\mathrm{Wd}$ at different grades and the marginal effect of the LST, the distance with a maximum ME of the synergistic cooling effect of the blue-green space in the Width-I river zone was $400 \mathrm{~m}$ and its threshold distance was $600 \mathrm{~m}$. The distances with maximum ME of the blue-green space in the Width-II, Width-III, and Width-III rivers were $765 \mathrm{~m}, 630 \mathrm{~m}$, and $900 \mathrm{~m}$, respectively, and the threshold distances were $900 \mathrm{~m}, 1200 \mathrm{~m}$, and $1395 \mathrm{~m}$, respectively.

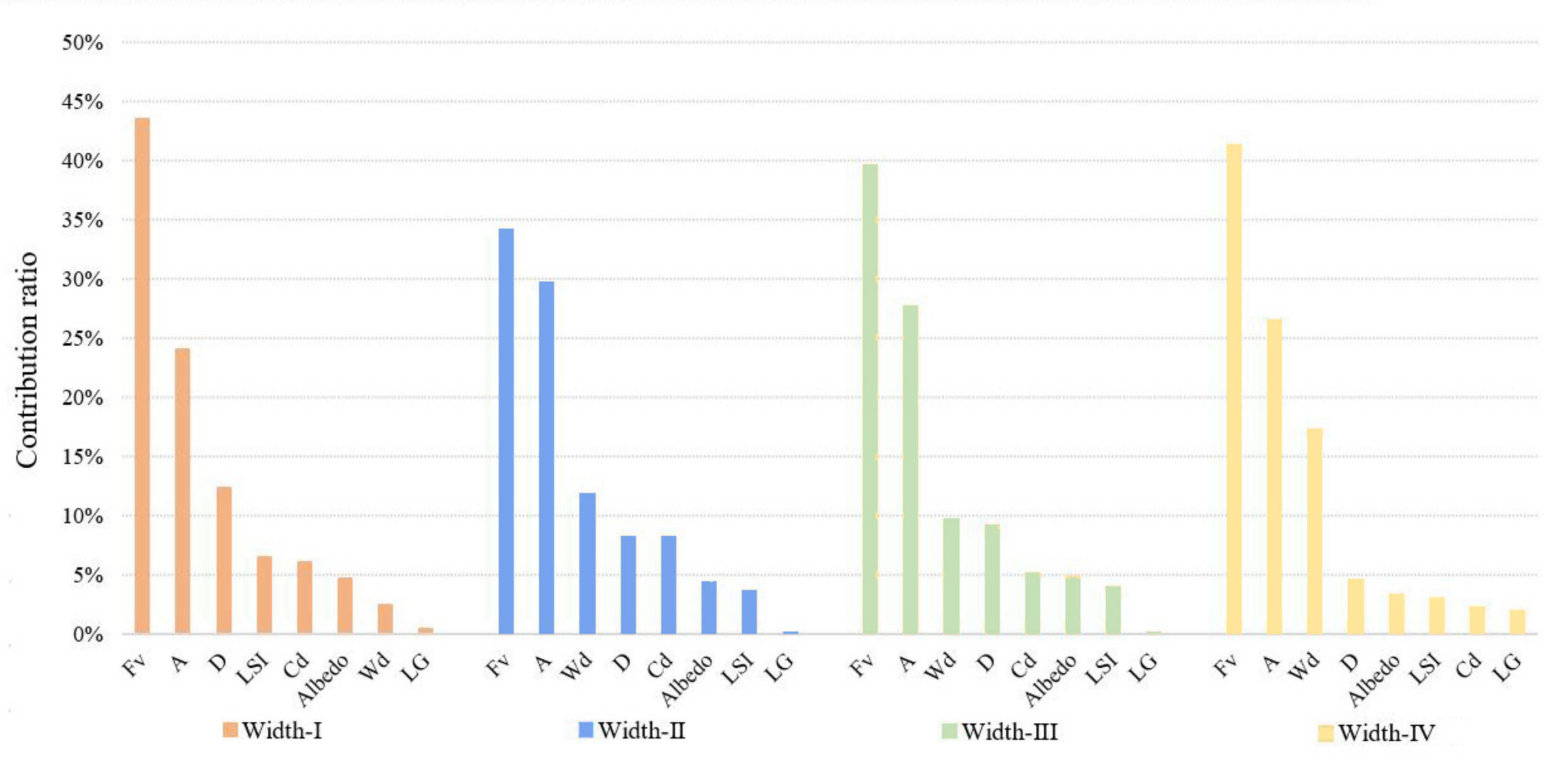

Figure 22. Contribution ratios of each spatial variable to the LST in rivers with different width grades.

The distribution status of the green space in the waterfront zone of the Width-II and Width-III rivers slightly affected the contribution ratios in this study. The maximum impact range of the WCI was larger for Width-III rivers than that for the Width-II rivers. Moreover, the curve inclination of the Width-III rivers was larger than that of the Width-II rivers, which 
indicated that the intensity of the blue-green synergistic cooling effect was considerably higher than that of the second-level rivers. Therefore, a larger river width corresponded to a greater cooling effect. In general, a river width of more than $30 \mathrm{~m}$ was a notable cooling source for the city and the river width exhibited a gradually increasing influence on the contribution ratio of the cooling effect. In terms of the numerical relationship of the cooling intensity, the UCI for a large river width fluctuated slightly and was relatively stable.

\subsection{The Importance of Greenspace Morphological Factors in Waterfront Areas}

Authors should discuss the results and how they can be interpreted both from the perspective of previous studies and of the working hypotheses. The findings and their implications should be discussed in the broadest context possible. Future research directions may also be highlighted.

Through the BRT model analysis and comparative study, and considering the background of the river corridors with different grade widths, it was observed that the influence of the green space morphology on the LST in waterfront areas was significant. The research results showed that the effect of the morphological factors on the LST distribution was greater than that of the rivers. This feature could be clearly identified considering two aspects:

a. In the index system of the LST-related morphological factors of waterfront green spaces, Fv and area considerably influenced the LST. The total contribution ratio of the two factors was more than $60 \%$ and Fv was the primary factor affecting the LST, as observed in the previous studies [18].

b. In the river width classification studies, the $\mathrm{D}$ factor exhibited a negative correlation with the LST. In particular, the regression relationship between D and LST, and the ME was below zero for the Width-II and Width-IV rivers. This finding reflected the fact that the water cold island effect decreased with increasing D, but the synergy of the blue-green space increased the intensity of the marginal effect. When a constant negative correlation existed between the two aspects, the UGCI strengthened the UWCI, and the cooling values exceeded the attenuation values when D was large.

Furthermore, the morphological factors between the waterbodies and green spaces or among green space systems influenced the cooling effect. The LG factors and Cd relationship among the green space systems were analyzed (Figure 23). With the increase in the river-width grade, the LST values of the waterfront green space, according to the classification of the LG and Cd types, decreased. The LST values of the green space in the L-location were lower than those in the W-location and the LST values of green space with high Cd-types corresponded to the lowest values. Moreover, the comparative analysis of the $\mathrm{Cd}$ contribution ratio indicated that the impact of the Cd factors in the Width-I and Width-II river zones was significant. As the river width increased, the Cd effect attenuated, and the relative effect of $\mathrm{Cd}$ was quite low in the Width-IV river zone. Therefore, for small and medium rivers, the improvement of the green space connectivity degree is necessary to maximize the cooling island effect in the holistic waterfront area layout. 


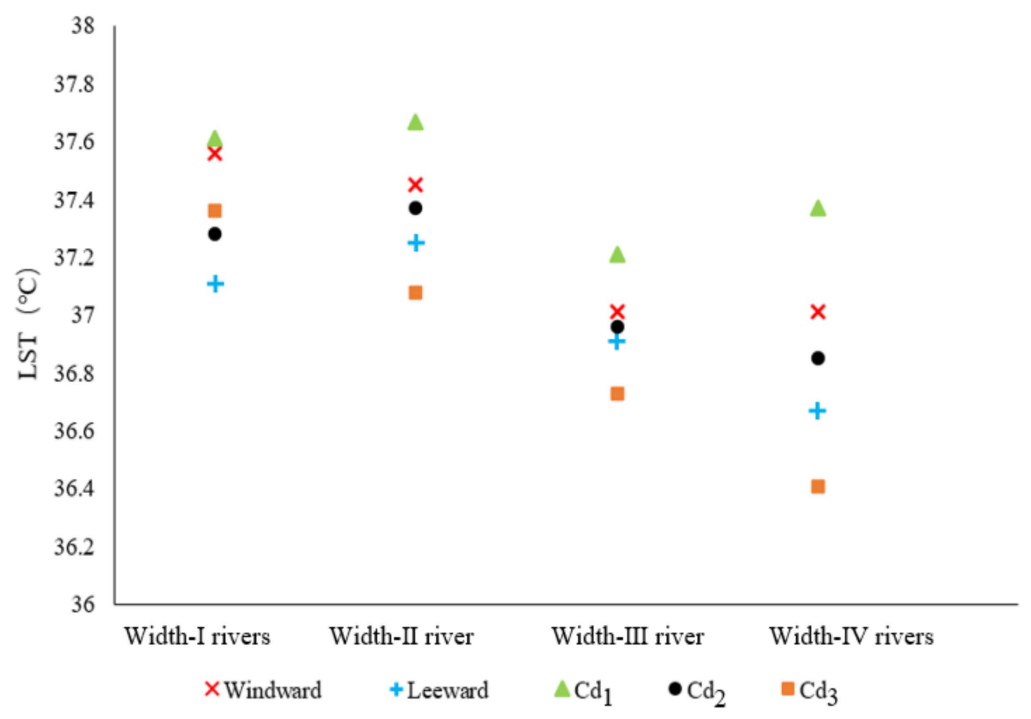

Figure 23. Correlation analysis between LST and LG or Cd factors of different grades of rivers.

Regardless of the width grade of the river, the MG types with the lowest LST were concluded to be $\mathrm{A}_{5} \mathrm{Fv}_{3} \mathrm{Cd}_{3} \mathrm{~L}$ (Figure 8, Figure 12, Figure 16, and Figure 20), with LST values below $34^{\circ} \mathrm{C}$. In addition, the $\mathrm{MG}$ types of $\mathrm{A}_{5} \mathrm{Fv}_{3} \mathrm{Cd}{ }_{3} \mathrm{~W}, \mathrm{~A}_{5} \mathrm{Fv}_{3} \mathrm{Cd}_{2} \mathrm{~L}$, and $\mathrm{A}_{4} \mathrm{Fv}_{3} \mathrm{Cd}{ }_{3} \mathrm{~L}$ exhibited a low LST. Therefore, MG types with the characteristics of large areas, high vegetation coverage, and high connectivity degrees were noted to have the highest cooling effect. The blue-green synergistic cooling effect was key to solving the thermal environment problems in plain river network cities during hot summers. A waterfront greenbelt with a certain width and high vegetation coverage can enhance the cooling synergistic effect, particularly in the D range with the maximum ME. Additionally, the moderate distribution of a large green space in the buffer zone and the formation of a continuous green space network can help induce a more significant blue-green synergistic cooling effect.

\subsection{Differences Compared to the Existing Studies}

In previous studies on the impact of distribution pattern characteristics of waterbodies and green spaces based on remote sensing images in thermal environments, raster data and the grid analysis method were mostly used to quantify the composition of land cover types (including water body and vegetation coverage) and other elements in the unit grid space. Then, conduct correlation analysis was conducted with their corresponding land surface temperature so as to obtain the influencing characteristics of the main cooling efficiencies of waterbodies and different types of green spaces [22,25,32]. For urban spatial planning and design, specific waterfront green spaces represent the spatial units. Their quantitative controlling of spatial morphological indices was aimed at providing the direct policy-making method for forming the best waterfront cooling network from the aspects of holistic spatial composition and morphology, as well as from the aspect of their spatial structure characteristics in the riverfront region. As there is a lack of real descriptions on the spatial attributes of actual features, it is obvious that unit raster data cannot provide direct and effective suggestions for spatial development. Our research formed a quantitative description of waterfront green spaces and analyzed the cooling correlation of spatial factors.

The BRT model has strong adaptability to datasets and can handle both continuous and categorical data, and can reflect the comprehensive interaction of variables. The cooling effect of the influencing factors of blue-green space depends on the morphological composition and spatial pattern elements, which has been verified by a large number of preliminary studies $[49,50]$. The correlation methods primarily analyzed the unilateral effect of indicators in an independent manner and did not comprehensively examine the combined effect of multiple indices [13,78]. Moreover, neither quantification of the specific 
contribution ratio of specific cooling influencing factors, nor further analyzation of the cooling threshold values of each factor were done. The regression results of the BRT model demonstrate the importance of the cooling impact of spatial factors and clearly describe the quantitative impact difference of the collaborative correlation of multi-dimensional spatial variable systems.

The synergistic cooling effect of blue-green spaces is a comprehensive and complex ecological process. More comprehensive spatial indices related to the spatial correlation index between waterbodies and green spaces must be combined to this study. The actual cooling effect of urban rivers and green spaces is complex, and the blue-green synergistic cooling effect should be examined considering the multi-dimensional spatial factors, including the morphological composition, spatial pattern, and blue-green ecological network elements. In particular, the $\mathrm{Cd}$ index represents the connectivity degree of the blue-green ecological landscape and the location of a green space represents the relative position of the green space against rivers. In this study, this index was adopted to comprehensively explain the morphological patterns of green spaces in the waterfront area and to refine the cooling efficiency of the green space types under the framework of the morphological indicators.

Compared with previous studies, this study had formed a set of innovative adopted tools and methods. First, the waterbody and green space data were obtained through artificial visual classification based on a high-precision Google satellite map and modified through artificial surveys. Compared with the software-based computer classification method, this method exhibits a higher precision [79]. In addition, the BRT machine learning method was adopted to quantify the influence of each factor on the LST and the cooling effect characteristics of the rivers on the green space to analyze the relationship between each factor and the LST. Third, to comprehensively study the combined effect of multiple factors, different structural and morphological factors were combined to group a variety of green space types; subsequently, the cooling characteristics of different structural and morphological green space types were discussed through an association analysis with the LST. This study summarized the characteristics of the waterfront green space pattern with the highest cooling effect. This study is in line with the requirements of the control index setting for planning and layout, and can provide optimal suggestions in actual local construction scenarios.

\subsection{Limitations of the Present Study}

Our research was aimed at studying the interaction between the cooling effect of riverfront green spaces and the structural composition of green spaces during a typical summer high-temperature period. The remote sensing data can only provide data in a fixed period of time during the diurnal period. The seasonal variation and differences between diurnal and nocturnal times in the synergistic cooling effect of waterbodies and green spaces has not been analyzed [80-82]. Future work can be aimed at performing a comparative analysis of different time variations regarding the cooling effect and obtaining more comprehensive results. Additionally, more diversified methods and tools, such as climate observation data and climate model simulation, should be used to obtain the mechanism of thermo-fluid dynamics for UHI mitigation at different spatial scales.

In addition, only certain widths of rivers have been selected to analyze the cooling effect on the LST of typical blue-green ecological spaces. Moreover, to examine the effect of the built surrounding environmental factors of the waterfront green space on the UCI, only the albedo factor has been considered as the consideration impact index. To conduct a more comprehensive and extensive study, it is necessary to differentiate the composition and structure of various land uses in the study area and to optimize the comprehensive policies to perform adaptive urban development.

\section{Conclusions}

The BRT model was used to estimate the relative contribution ratios of various morphological factors of the waterfront green space in four width-grade river zones to the 
LST. In all the river-width classifications, the green space coverage (contribution ratio of $32.7-49.2 \%$ ) and area (contribution ratio of $24.0-29.5 \%$ ) were the dominant factors affecting the LST. The width of the river and its contribution to the LST increased gradually from Width-I to Width-IV rivers. A larger width of the river corresponded to a greater distance threshold of the synergistic cooling effect. The threshold distance of the blue-green synergistic cooling effect for Width-I to Width-IV rivers was $600 \mathrm{~m}, 900 \mathrm{~m}, 1200 \mathrm{~m}$, and $1395 \mathrm{~m}$ (the furthest impact distance of the blue-green synergistic cooling effect), respectively.

Through the comparative analysis of the effects of multiple-combination morphological factors of waterfront green spaces, it was noted that a larger green space with higher coverage and higher connectivity, as well as the L-location at the river, corresponded to the least LST. The MG types of green spaces with a high green space coverage and large area generally had low LST distributions. The green spaces located on the leeward side of the river were considerably affected by the river cooling resource and had a higher cooling effect. The green space with the high connectivity degree exhibited enhanced air flow circulation inside the ecological space network, which strengthened the cooling effect. The enhanced connectivity of ecological networks, which can improve urban ventilation, can help optimize the waterfront spatial pattern of green space systems in cities with intensive river networks to mitigate UHIs.

Author Contributions: Conceptualization, Y.J. and T.S.; funding acquisition, Y.J. and T.S.; investigation, Y.J. and J.H.; data collection, J.H. and H.W.; data analysis, Y.J. and J.H.; methodology, Y.J.; project administration, Y.J.; writing — original draft preparation, Y.J. and J.H.; writing—review and editing, Y.J. All authors have read and agreed to the published version of the manuscript.

Funding: This research study was funded by the National Natural Science Foundation of China project (grant numbers 51878279, 51878418, and 51578344).

Institutional Review Board Statement: Not applicable.

Informed Consent Statement: Not applicable.

Acknowledgments: This research study was supported by the National Natural Science Foundation of China project (grant numbers 51878279 and 51878418). The authors would like to thank the editor and the anonymous reviewers for their helpful comments.

Conflicts of Interest: The authors declare no conflict of interest.

$\begin{array}{ll}\text { Abbreviations } & \\ \text { urban heat island } & \text { UHI } \\ \text { urban cooling effect } & \text { UCI } \\ \text { urban cooling island of green space } & \text { UGCI } \\ \text { waterbody cooling island } & \text { WCI } \\ \text { land surface temperature } & \text { LST } \\ \text { boosted regression trees } & \text { BRT } \\ \text { morphological group } & \text { MG } \\ \text { marginal effect } & \text { ME } \\ \text { normalized difference vegetation index } & \text { NDVI } \\ \text { normalized difference built-up index } & \text { NDBI } \\ \text { sky view factors } & \text { SVF } \\ \text { United States geological survey } & \text { USGS } \\ \text { thermal infrared sensor } & \text { TIRS } \\ \text { fast line-of-sight atmospheric analysis of spectral hypercubes } & \text { FLAASH } \\ \text { radiative transfer equation } & \text { RTE } \\ \text { mono-window algorithm } & \text { MWA }\end{array}$




$\begin{array}{ll}\text { single-channel method } & \text { SCM } \\ \text { ground control points } & \text { GCPs } \\ \text { area } & \mathrm{A} \\ \text { landscape shape index } & \mathrm{LSI} \\ \text { fractional cover values of vegetation space } & \mathrm{Fv} \\ \text { width of river } & \mathrm{Wd} \\ \text { distance to riverbank } & \mathrm{D} \\ \text { probability of connectivity } & \mathrm{PC} \\ \text { decrease in the probability of connectivity } & \mathrm{dPC} \\ \text { connectivity degree } & \mathrm{Cd} \\ \text { location of greenspace } & \mathrm{LG}\end{array}$

\section{References}

1. Oke, T.R. The energetic basis of the urban heat island. Q. J. R. Meteorol. Soc. 1982, 108, 1-24. [CrossRef]

2. Voogt, J.A.; Oke, T.R. Thermal remote sensing of urban climates. Remote Sens. Environ. 2003, 86, 370-384. [CrossRef]

3. Zhao, S.; Zhou, D.; Liu, S. Data concurrency is required for estimating urban heat island intensity. Environ. Pollut. 2016, 208, 118-124. [CrossRef]

4. Aflaki, A.; Mirnezhad, M.; Ghaffarianhoseini, A.; Ghaffarianhoseini, A.; Omrany, H.; Wang, Z.-H.; Akbari, H. Urban heat island mitigation strategies: A state-of-the-art review on Kuala Lumpur, Singapore and Hong Kong. Cities 2017, 62, 131-145. [CrossRef]

5. Skelhorn, C.; Lindley, S.; Levermore, G. The impact of vegetation types on air and surface temperatures in a temperate city: A fine scale assessment in Manchester, UK. Landsc. Urban Plan. 2014, 121, 129-140. [CrossRef]

6. Grimmond, C.S.B.; Oke, T.R. Heat storage in urban areas: Local-scale observations and evaluation of a simple model. J. Appl. Meteorol. 1999, 38, 922-940. [CrossRef]

7. Sailor, D.J. A review of methods for estimating anthropogenic heat and moisture emissions in the urban environment. Int. J. Climatol. 2011, 31, 189-199. [CrossRef]

8. Tallis, M.; Taylor, G.; Sinnett, D.; Freer-Smith, P. Estimating the removal of atmospheric particulate pollution by the urban tree canopy of London, under current and future environments. Landsc. Urban Plan. 2011, 103, 129-138. [CrossRef]

9. Akbari, H.; Pomerantz, M.; Taha, H. Cool surfaces and shade trees to reduce energy use and improve air quality in urban areas. Sol. Energy 2001, 70, 295-310. [CrossRef]

10. Taha, H. Urban climates and heat islands: Albedo, evapotranspiration, and anthropogenic heat. Energy Build. 1997, 25, 99-103. [CrossRef]

11. Chan, E.Y.Y.; Goggins, W.B.; Kim, J.J.; Griffiths, S.M. A study of intracity variation of temperature-related mortality and socioeconomic status among the Chinese population in Hong Kong. J. Epidemiol. Community Health 2010, 66, 322-327. [CrossRef] [PubMed]

12. Chen, A.; Yao, L.; Sun, R.; Chen, L. How many metrics are required to identify the effects of the landscape pattern on land surface temperature? Ecol. Indic. 2014, 45, 424-433. [CrossRef]

13. Moyer, A.N.; Hawkins, T.W. River effects on the heat island of a small urban area. Urban Clim. 2017, 21, 262-277. [CrossRef]

14. Gunawardena, K.R.; Wells, M.J.; Kershaw, T. Utilising green and bluespace to mitigate urban heat island intensity. Sci. Total Environ. 2017, 584-585, 1040-1055. [CrossRef] [PubMed]

15. Wu, J.; Li, C.; Zhang, X.; Zhao, Y.; Liang, J.; Wang, Z. Seasonal variations and main influencing factors of the water cooling islands effect in Shenzhen. Ecol. Indic. 2020, 117, 106699. [CrossRef]

16. Theeuwes, N.E.; Solcerová, A.; Steeneveld, G.J. Modeling the influence of open water surfaces on the summertime temperature and thermal comfort in the city. J. Geophys. Res. Atmos. 2013, 118, 8881-8896. [CrossRef]

17. Yu, Z.; Yang, G.; Zuo, S.; Jørgensen, G.; Koga, M.; Vejre, H. Critical review on the cooling effect of urban blue-green space: A threshold-size perspective. Urban For. Urban Green. 2020, 49, 126630. [CrossRef]

18. Fan, H.; Yu, Z.; Yang, G.; Liu, T.Y.; Hung, C.H.; Vejre, H. How to cool hot-humid (Asian) cities with urban trees? An optimal landscape size perspective. Agric. For. Meteorol. 2019, 265, 338-348. [CrossRef]

19. Du, H.; Song, X.; Jiang, H.; Kan, Z.; Wang, Z.; Cai, Y. Research on the cooling island effects of water body: A case study of Shanghai, China. Ecol. Indic. 2016, 67, 31-38. [CrossRef]

20. Lin, B.-S.; Lin, Y.-J. Cooling Effect of Shade Trees with Different Characteristics in a Subtropical Urban Park. HortScience 2010, 45, 83-86. [CrossRef]

21. Skoulika, F.; Santamouris, M.; Kolokotsa, D.; Boemi, S.-N. On the thermal characteristics and the mitigation potential of a medium size urban park in Athens, Greece. Landsc. Urban Plan. 2014, 123, 73-86. [CrossRef]

22. Yu, Z.; Guo, X.; Jørgensen, G.; Vejre, H. How can urban green spaces be planned for climate adaptation in subtropical cities? Ecol. Indic. 2017, 82, 152-162. [CrossRef]

23. Jaganmohan, M.; Knapp, S.; Buchmann, C.; Schwarz, N. The Bigger, the Better? The Influence of Urban Green Space Design on Cooling Effects for Residential Areas. J. Environ. Qual. 2016, 45, 134-145. [CrossRef] [PubMed]

24. Yang, G.; Yu, Z.; Jørgensen, G.; Vejre, H. How can urban blue-green space be planned for climate adaption in high-latitude cities? A seasonal perspective. Sustain. Cities Soc. 2020, 53, 101932. [CrossRef] 
25. Sun, R.; Chen, L. How can urban water bodies be designed for climate adaptation? Landsc. Urban Plan. 2012, 105, 27-33. [CrossRef]

26. Cao, X.; Onishi, A.; Chen, J.; Imura, H. Quantifying the cool island intensity of urban parks using ASTER and IKONOS data. Landsc. Urban Plan. 2010, 96, 224-231. [CrossRef]

27. Cuculic, M.; Surdonja, S.; Babic, S.; Tibljas, A.D. Possible Locations for Cool Pavement Use in City of Rijeka. In Proceedings of the 4th EPAM, European Pavement and Asset Management Conference, Malmö, Sweden, 5-7 September 2012.

28. Sharma, R.; Pradhan, L.; Kumari, M.; Bhattacharya, P. Assessing urban heat islands and thermal comfort in Noida City using geospatial technology. Urban Clim. 2021, 35, 100751. [CrossRef]

29. Firozjaei, M.K.; Sedighi, A.; Firozjaei, H.K.; Kiavarz, M.; Homaee, M.; Arsanjani, J.J.; Makki, M.; Naimi, B.; Alavipanah, S.K. A historical and future impact assessment of mining activities on surface biophysical characteristics change: A remote sensing-based approach. Ecol. Indic. 2021, 122, 107264. [CrossRef]

30. Zhou, L.; Shi, W.; Xue, W.; Wang, T.; Ge, Z.; Zhou, W.; Zhong, Y. Relationship between vegetation structure and the temper-ature and moisture in urban green spaces of Shanghai. Chin. J. Ecol. 2005, 24, 1102-1105. (In Chinese)

31. Wang, Y.J.; Yan, F.; Zhang, P.Q.; Ren, F.M. Study on urban heat island changes in Beijing using normalized difference vegetation index and Albedo Data. Res. Environ. Sci. 2009, 22, 215-220. [CrossRef]

32. Shih, W.-Y. Greenspace patterns and the mitigation of land surface temperature in Taipei metropolis. Habitat Int. 2017, 60, 69-80. [CrossRef]

33. Masoudi, M.; Tan, P.Y. Multi-year comparison of the effects of spatial pattern of urban green spaces on urban land surface temperature. Landsc. Urban Plan. 2019, 184, 44-58. [CrossRef]

34. Webb, B.W.; Zhang, Y. Spatial and seasonal variability in the components of the river heat budget. Hydrol. Process. 1997, 11, 79-101. [CrossRef]

35. Xue, Z.; Hou, G.; Zhang, Z.; Lyu, X.; Jiang, M.; Zou, Y.; Shen, X.; Wang, J.; Liu, X. Quantifying the cooling-effects of urban and peri-urban wetlands using remote sensing data: Case study of cities of Northeast China. Landsc. Urban Plan. 2019, 182, 92-100. [CrossRef]

36. Murakawa, S.; Sekine, T.; Narita, K.-I.; Nishina, D. Study of the effects of a river on the thermal environment in an urban area. Energy Build. 1991, 16, 993-1001. [CrossRef]

37. Yue, W.; Xu, L. Thermal environment effect of urban water landscape. Acta Ecol. Sinica. 2013, 33, 1852-1859. [CrossRef]

38. Jiang, L.; Liu, S.; Liu, C.; Feng, Y. How do urban spatial patterns influence the river cooling effect? A case study of the Huangpu Riverfront in Shanghai, China. Sustain. Cities Soc. 2021, 69, 102835. [CrossRef]

39. Hathway, E.; Sharples, S. The interaction of rivers and urban form in mitigating the Urban Heat Island effect: A UK case study. Build. Environ. 2012, 58, 14-22. [CrossRef]

40. Syafii, N.I.; Ichinose, M.; Wong, N.H.; Kumakura, E.; Jusuf, S.K.; Chigusa, K. Experimental Study on the Influence of Urban Water Body on Thermal Environment at Outdoor Scale Model. Procedia Eng. 2016, 169, 191-198. [CrossRef]

41. Yang, K.; Tang, M.; Liu, Y.; Wu, A.; Fan, Q. Analysis of Microclimate Effects around River and Waterbody in Shanghai Urban District. J. East China Norm. Univ. (Nat. Sci.) 2004, 3, 105-114. (In Chinese) [CrossRef]

42. Jiang, Y.; Song, D.; Shi, T.; Han, X. Adaptive Analysis of Green Space Network Planning for the Cooling Effect of Residential Blocks in Summer: A Case Study in Shanghai. Sustainability 2018, 10, 3189. [CrossRef]

43. Liu, B.Y.; Lin, J. Study on Relationship between Microclimate and Space Section of Urban Waterfront Green Belt A Case Study of Riverfront Green Belt in Suzhou and Shanghai. Landsc. Archit. 2015, 6, 46-54. (In Chinese) [CrossRef]

44. Kundu, S.; Khare, D.; Mondal, A. Individual and combined impacts of future climate and land use changes on the water balance. Ecol. Eng. 2017, 105, 42-57. [CrossRef]

45. Herb, W.R.; Stefan, H.G. Dynamics of vertical mixing in a shallow lake with submersed macrophytes. Water Resour. Res. 2005, 41, 293-307. [CrossRef]

46. Li, C.; Yu, C.W. Mitigation of urban heat development by cool island effect of green space and water body. Refrig. Air Cond. 2016, 30, 262-266. (In Chinese) [CrossRef]

47. Dong, J.; Chen, J.; Brosofske, K.; Naiman, R. Modelling air temperature gradients across managed small streams in western Washington. J. Environ. Manag. 1998, 53, 309-321. [CrossRef]

48. Yoon, J.; Chen, H.; Ooka, R.; Kato, S.; Hsieh, C.M.; Ishizaki, R.; Miisho, K.; Kudoh, R. Design of the Outdoor Thermal Environment for a Sustainable Riverside Housing Complex Using a Coupled Simulation of cfd and Radiation Transfer. Conf. Seoul Building. 2007, pp. 477-482. Available online: https://www.researchgate.net/publication/237620858_Design_of_the_ Outdoor_Thermal_Environment_for_a_Sustainable_Riverside_Housing_Complex_using_a_Coupled_Simulation_of_CFD_ and_Radiation_Transfer (accessed on 2 February 2021).

49. Heggem, D.T.; Edmonds, C.M.; Neale, A.C.; Bice, L.; Jones, K.B. A landscape ecology assessment of the Tensas River Basin. Environ. Monit. Assess. 2000, 64, 41-54. [CrossRef]

50. Jiang, Y.; Jiang, S.; Shi, T. Comparative Study on the Cooling Effects of Green Space patterns in Waterfront Build-Up Blocks: An Experience from Shanghai. Int. J. Environ. Res. Public Health 2020, 17, 8684. [CrossRef] [PubMed]

51. Jiménez-Muñoz, J.C.; Sobrino, J.A.; Skokovic, D.; Mattar, C.; Cristóbal, J. Land Surface Temperature Retrieval Methods From Landsat-8 Thermal Infrared Sensor Data. IEEE Geosci. Remote Sens. Lett. 2014, 11, 1840-1843. [CrossRef] 
52. Peng, J.; Xie, P.; Liu, Y.; Ma, J. Urban thermal environment dynamics and associated landscape pattern factors: A case study in the Beijing metropolitan region. Remote Sens. Environ. 2016, 173, 145-155. [CrossRef]

53. Weather Underground Web. Hongqiao Daily Observation in Shanghai. 2017. Available online: https: / www.wunderground. com/history/daily/cn/shanghai-hongqiao/ZSSS/date/2017-8-24 (accessed on 8 January 2020).

54. Zhang, J.; Liu, H. Spatial-temporal Evolution of Urban Heat Island Effect in Shanghai from 2000 to 2017. Environ. Sci. Surv. 2020, $39,19-36$.

55. Shanghai Water Authority. 2017 Shanghai River Channel (Lake) Report. Available online: http://swj.sh.gov.cn/hhbg/ (accessed on 15 January 2020).

56. Yu, X.; Guo, X.; Wu, Z. Land Surface Temperature Retrieval from Landsat 8 TIRS-Comparison between Radiative Transfer Equation-Based Method, Split Window Algorithm and Single Channel Method. Remote Sens. 2014, 6, 9829-9852. [CrossRef]

57. Qi, J.; Marsett, R.; Moran, M.; Goodrich, D.; Heilman, P.; Kerr, Y.; Dedieu, G.; Chehbouni, A.; Zhang, X. Spatial and temporal dynamics of vegetation in the San Pedro River basin area. Agric. For. Meteorol. 2000, 105, 55-68. [CrossRef]

58. Yang, H. Experience of Budget Estimate Compilation for small and medium sized river regulation projects in Shanghai. Water Resour. Plan. Des. 2015, 10, 112-114. (In Chinese) [CrossRef]

59. The People's Government of Zhejiang Province. DB33/T 614-2016 Construction Code For River Way. Available online: http:/ / zjjcmspublic.oss-cn-hangzhou-zwynet-d01-a.internet.cloud.zj.gov.cn/jcms_files/jcms1/web2980/site/attach/0/228b0 2f04d344274b08598cf00daa98f.pdf (accessed on 10 July 2021).

60. Ji, P.; Zhu, C.-Y.; Li, S.-H. Effects of urban river width on the temperature and humidity of nearby green belts in summer. Chin. J. Appl. Ecol. 2012, 23, 679-684.

61. Teng, M. Planning Ecological Security Patterns in a Rapidly Urbanizing Context: A Case Study in Wuhan, China; Huazhong Agricultural University: Wuhan, China, 2011. [CrossRef]

62. Purevdorj, T.; Tateishi, R.; Ishiyama, T.; Honda, Y. Relationships between percent vegetation cover and vegetation indices. Int. J. Remote Sens. 1998, 19, 3519-3535. [CrossRef]

63. Gitelson, A.A.; Kaufman, Y.J.; Stark, R.; Rundquist, D. Novel algorithms for remote estimation of vegetation fraction. Remote Sens. Environ. 2002, 80, 76-87. [CrossRef]

64. Fang, J.; Zhou, X. Inversion and Monitoring of Vegetation Coverage in Yinchuan City Based on Remote Sensing Images and NDVI Threshold Method. Water Sav. Irrig. 2014, 11, 68-72. (In Chinese) [CrossRef]

65. Wang, S.; Grant, R.F.; Verseghy, D.L.; Black, T.A. Modelling Carbon Dynamics of Boreal Forest Ecosystems Using the Canadian Land Surface Scheme. Clim. Chang. 2002, 55, 451-477. [CrossRef]

66. Dickinson, R.E. Land processes in climate models. Remote Sens. Environ. 1995, 51, 27-38. [CrossRef]

67. Liang, S. Narrowband to broadband conversions of land surface albedo I: Algorithms. Remote Sens. Environ. 2001, 76, 213-238. [CrossRef]

68. Saura, S.; Pascual-Hortal, L. A new habitat availability index to integrate connectivity in landscape conservation planning: Comparison with existing indices and application to a case study. Landsc. Urban Plan. 2007, 83, 91-103. [CrossRef]

69. Jaeger, J.A. Landscape division, splitting index, and effective mesh size: New measures of landscape fragmentation. Landsc. Ecol. 2000, 15, 115-130. [CrossRef]

70. Bodin, Ö.; Saura, S. Ranking individual habitat patches as connectivity providers: Integrating network analysis and patch removal experiments. Ecol. Model. 2010, 221, 2393-2405. [CrossRef]

71. Katz, J.S. Geographical proximity and scientific collaboration. Science 1994, 31, 31-43. [CrossRef]

72. Elith, J.; Leathwick, J.R.; Hastie, T. A working guide to boosted regression trees. J. Anim. Ecol. 2008, 77, 802-813. [CrossRef] [PubMed]

73. Chen, L.; Guo, X.; Han, Y.; Zhu, Q. Research on Spatio-temporal Characteristics and Driving Factors of Urban Expansion in Nanchang City Based on BRT Model. Res. Environ. Yangtze Basin 2020, 29, 322-333. (In Chinese) [CrossRef]

74. De'Ath, G. Boosted trees for ecological modeling and prediction. Ecology 2007, 88, 243-251. [CrossRef]

75. Grunwald, L.; Schneider, A.-K.; Schroder, B.; Weber, S. Predicting urban cold-air paths using boosted regression trees. Landsc. Urban Plan. 2020, 201, 103843. [CrossRef]

76. Hu, Y.; Dai, Z.; Guldmann, J.-M. Modeling the impact of 2D/3D urban indicators on the urban heat island over different seasons: A boosted regression tree approach. J. Environ. Manag. 2020, 266, 110424. [CrossRef]

77. Jiang, H.; Liao, S.; Erike, A. Statistical analysis on relationship between soil surface temperature and air temperature. Chin. J. Agrometeorol. 2004, 25, 1-4. (In Chinese) [CrossRef]

78. Peng, J.; Jia, J.; Liu, Y.; Li, H.; Wu, J. Seasonal contrast of the dominant factors for spatial distribution of land surface temperature in urban areas. Remote Sens. Environ. 2018, 215, 255-267. [CrossRef]

79. Kong, F.; Yin, H.; James, P.; Hutyra, L.R.; He, H.S. Effects of spatial pattern of greenspace on urban cooling in a large metropolitan area of eastern China. Landsc. Urban Plan. 2014, 128, 35-47. [CrossRef]

80. Shi, X.; Wu, T.; Xu, D.; Liu, Y.; Su, J.; Xiao, Y. Micro-climate in Forest Park of Maofeng Mountains in Guangzhou. J. Chin. Urban For. 2005, 3, 46-48. (In Chinese) [CrossRef]

81. Zhang, Y.; Bao, W.; Yu, Q.; Ma, W. Study on seasonal variations of the urban heat island and its in-terannual changes in a typical Chinese megacity. Chin. J. Geophys. 2012, 55, 1121-1128. (In Chinese) [CrossRef]

82. Pan, L.; Chen, J. The Simulation of "Cold Island Effect" over Oasis at Night. Sci. Atmos. Sinica 1997, 21, 39-48. (In Chinese) 